WORKING PAPER 205

US Monetary Policy in a Globalized World

Jesús Crespo Cuaresma, Gernot Doppelhofer, Martin Feldkircher, Florian Huber 
The Working Paper series of the Oesterreichische Nationalbank is designed to disseminate and to provide a platform for discussion of either work of the staff of the OeNB economists or outside contributors on topics which are of special interest to the OeNB. To ensure the high quality of their content, the contributions are subjected to an international refereeing process. The opinions are strictly those of the authors and do in no way commit the OeNB.

The Working Papers are also available on our website (http://www.oenb.at) and they are indexed in RePEc (http://repec.org/).

Publisher and editor

Editorial Board

of the Working Papers

\section{Coordinating editor}

Design

DVR 0031577

ISSN 2310-5321 (Print)

ISSN 2310-533X (Online)

(C) Oesterreichische Nationalbank, 2016. All rights reserved.

Oesterreichische Nationalbank

Otto-Wagner-Platz 3, 1090 Vienna, Austria

PO Box 61, 1011 Vienna, Austria

www.oenb.at

oenb.info@oenb.at

Phone (+43-1) 40420-6666

Fax (+43-1) 40420-046698

Doris Ritzberger-Grünwald, Ernest Gnan, Martin Summer

Martin Summer

Communications and Publications Division 


\title{
US Monetary Policy in a Globalized World*
}

\author{
Jesús Crespo Cuaresma1 ${ }^{1,45,6}$, Gernot Doppelhofer ${ }^{2}$, Martin Feldkircher ${ }^{3}$, and Florian \\ Huber $^{1}$ \\ ${ }^{1}$ Vienna University of Economics and Business (WU) \\ ${ }^{2}$ Norwegian School of Economics (NHH) \\ ${ }^{3}$ Oesterreichische Nationalbank (OeNB) \\ ${ }^{4}$ International Institute of Applied System Analysis (IIASA) \\ ${ }^{5}$ Wittgenstein Center for Demography and Global Human Capital (IIASA,VID/OEAW,WU) \\ ${ }^{6}$ Austrian Institute of Economic Research (WIFO)
}

\begin{abstract}
We analyze the interaction between monetary policy in the US and the global economy proposing a new class of Bayesian global vector autoregressive models that accounts for time-varying parameters and stochastic volatility (TVP-SV-GVAR). We find that a contractionary US monetary policy shock leads to a persistent fall in international output, a drop in global inflation rates, a rise in international interest rates and a strengthening of the US dollar in real terms. There is considerable evidence for heterogeneity of spillovers across countries, as well as for changes in the transmission of monetary policy shocks over time. We also examine the reverse question, namely how US monetary policy responds to international shocks. Here we find that US short-term rates decrease significantly in response to a monetary policy tightening abroad or a negative shock to foreign real GDP growth.
\end{abstract}

Keywords: Global vector autoregression, time-varying parameters, stochastic volatility, monetary policy, international spillovers

JEL Codes: $\quad$ C30, E52, F41

\footnotetext{
*Corresponding author: Jesús Crespo Cuaresma, Vienna University of Economics and Business, Phone: +43(1)31336-4530. E-mail: jcrespo@wu.ac.at. The opinions expressed in this paper are those of the authors and do not necessarily reflect the official viewpoint of the Oesterreichische Nationalbank or the Eurosystem. The authors thank Sylvia Frühwirth-Schnatter, Gregor Kastner, Dubravko Mihaljek, Philipp Piribauer and Mike West as well as participants at research seminars at the Norwegian School of Economics, the OeNB, the NBER-NSF 2015 time series workshop and the 9th International Conference on Computational and Financial Econometrics (CFE 2015) for helpful comments on an earlier draft of this paper Support by funds of the Jubiläumsfonds of the Oesterreichische Nationalbank (project number 16244) is gratefully acknowledged.
} 


\section{Non-technical summary}

The US economy plays a dominant role in shaping global macroeconomic and financial conditions. When in mid-2013 market participants started speculating about the timing of the US Federal Reserve's (Fed) exit from accommodative monetary policy, this propelled global volatility and triggered an adverse shift of market sentiment towards emerging markets. These spillovers from US monetary policy are well documented in the literature. They might have even intensified over the last decades on the back of rising economic and financial globalization.

There is also a reverse perspective to monetary policy and globalization. The rise in global interconnectedness could imply less independence and control to make effective policy. Not surprisingly, monetary policymakers have taken an active interest in the extent to which increased globalization affects their ability to independently set monetary policy. But not only policymakers in the countries of shock-origin are concerned of potential negative effects that feed back into their economy, so-called spillbacks. Also for the receiving economy it is of ample importance to investigate both ways, spillovers and spillbacks to draw a more complete picture of how external shocks propagate internationally. So far, a consensus seems to have formed that globalization has added another layer of complexity to the conduct of monetary policy, but empirical investigation is still scarce.

In this contribution we hence assess the dynamic relationship between US monetary policy and the world economy over time making use of a new class of global macroeconomic models. Within this modelling framework, we examine both spillovers from US monetary policy to global output and how US short-term interest rates adjust to external shocks. This framework also allows us to examine whether the transmission from and to the US economy has significantly changed over time.

We find that spillovers from a contractionary US monetary policy shock lead to (a) a persistent fall in global real activity, (b) a drop in global inflation rates together with (c) a rise in global nominal interest rates, and (d) a real appreciation of the US dollar. There is also a considerable degree of heterogeneity of the spillovers across economies, as well as for a changing transmission of monetary policy shocks at the global level over time. For most variables, the global response to US monetary policy has been larger during the period from the mid-1990s to mid-2000s, while effects on output dampened during the period of the global financial crisis. Looking at how US interest rates change in response to foreign shocks, we find evidence for a decrease in US short-term rates when monetary policy tightens or real GDP growth decelerates abroad. There is less evidence of other types of foreign shocks to impact US short-term rates significantly. 
“... effective monetary policy making now requires taking into account a diverse set of global influences, many of which are not fully understood"

Ben Bernanke Globalization and Monetary Policy. Speech at the Fourth Economic Summit, Stanford, 2007

\section{Introduction}

Economic theory has long recognized the interdependence of national economies. Models such as the Mundell-Fleming framework or microfounded New Keynesian approaches describe the effects that shocks to one economy may have on its trading partners (Kamin, 2010). These models, however, have often been interpreted as only being valid for small open economies. Theory predicts that large and rather closed economies such as the US are more insulated from foreign shocks, especially if they pursue a flexible exchange rate regime that can serve as a buffer to external shocks. This line of thinking has also been reflected in the specifications used for monetary policy rules that describe the behavior of the US Federal Reserve in setting its monetary policy stance. One of the most prominent monetary policy reaction functions, the Taylor rule (Taylor, 1993), describes monetary policy directly in terms of the two major operational objectives of monetary policy, domestic inflation and economic growth. Among others, Orphanides (2003) finds that the simple Taylor rule serves as a particularly good description of Federal Reserve policies virtually since the founding of the institution. According to the standard Taylor rule, the US Fed sets monetary policy in response to developments of domestic macroeconomic variables and independently of other external factors. In recent years, however, the ability of monetary policy in the world's largest economies to independently control monetary policy objectives has been put into question (Kamin, 2010). Not surprisingly, monetary policymakers have taken an active interest in the extent to which increased globalization affects their ability to independently set monetary policy.

The implications of increased globalization on the policy behavior of the Fed itself have been significantly less researched. The trend in financial globalization may have increased the importance of external factors for domestic monetary conditions in the US. This, in turn, would imply less independence and control on setting domestic interest rates to successfully shape domestic financial and economic conditions (Kamin, 2010). Monetary policy in a globalized world could be modeled directly by expanding the Taylor rule to feature international factors such as global output. Alternatively, one could think of the Fed reacting to external shocks via its response to domestic growth, which can be reasonably argued to be (at least partly) influenced by foreign (demand) shocks.

To address both of these questions, accounting for changes in the economic environment and the Fed reaction function seems essential. Among researchers, a consensus has emerged concerning the fact that monetary policy in the US has changed over the last three decades (Sims and Zha, 2006). Variation in the implementation of monetary policy and its effectiveness might be driven by several factors, including regulatory changes and changes in domestic and global macroeconomic and financial market conditions. In addition to changes in the re- 
action function of the Fed, changes in the economic environment can affect the outcome of monetary policy both in the USA and globally. In particular uncertainty, understood as the time-varying component of the volatility of economic shocks, has been shown to be an important factor explaining the dynamics of real economic activity (Bloom, 2009; FernándezVillaverde et al., 2011).

In this contribution, we assess the dynamic relationship between US monetary policy and the world economy over time making use of a new class of global macroeconomic models. We augment the global vector autoregressive model put forth in Pesaran et al. (2004) to allow for changes in parameters and error variances. The newly developed time-varying parameter stochastic volatility global vector autoregressive model (TVP-SV-GVAR) is then estimated using Bayesian methods for a global sample corresponding to approximately $80 \%$ of global output. To cope with such a data-rich environment efficiently from a computational point of view, we draw on recent contributions on Cholesky stochastic volatility models proposed by Lopes et al. (2013). Within this modeling framework, we examine both spillovers from US monetary policy to global output and how the Fed reacts to external shocks. We address changes in spillovers over time to judge whether the transmission from and to the US has significantly changed in the last decades.

Our results can be summarized as follows: First, a contractionary shock to US monetary policy tends to imply (a) a persistent global contraction in real activity, (b) a drop in global inflation rates together with (c) a rise in global nominal interest rates, and (d) a real appreciation of the US dollar. The estimated effects are in line with the existing empirical literature on the effects of shocks to monetary policy originated in the US on other economies (see Feldkircher and Huber, 2016). Second, we find evidence for heterogeneity of the spillovers across economies, as well as for a changing transmission of monetary policy shocks at the global level over time. For most variables, the global response to US monetary policy has been larger during the period from the mid-1990s to mid-2000s, while effects on output dampened during the period of the global financial crisis. On the other hand, US monetary policy responds to foreign monetary policy shocks and negative foreign real GDP growth shocks by lowering US domestic rates. There is less evidence of foreign inflation shocks and exchange rate shocks calibrated as a strengthening of the US dollar to impact domestic short-term rates significantly.

The paper is structured as follows. Section 2 presents the econometric framework including the Bayesian estimation strategy and the necessary prior specifications. Section 3 presents the data, while section 4 discusses the results. Finally, section 5 concludes.

\section{Econometric framework: The TVP-SV-GVAR specification}

To assess the dynamic transmission mechanism between US monetary policy and the global economy, we develop a global VAR model featuring time-varying parameters and stochastic volatility (TVP-SV-GVAR model). The TVP-SV-GVAR model is estimated using a broad panel of countries and macroeconomic aggregates, thus providing a truly global and flexible representation of the world economy. In general, the structure of a GVAR model implies two distinct stages in the estimation process. In the first, $N+1$ country-specific multivariate time series models are estimated, each of them including exogenous regressors that aim to capture 
cross-country linkages. In the second stage, these models are combined using country weights to form a global model that is used to carry out impulse response analysis or forecasting.

\subsection{The global vector autoregressive model with time-varying parameters}

Let the endogenous variables for country $i=0, \ldots, N$ be contained in a $k_{i} \times 1$ vector $y_{i t}=\left(y_{i 1, t}, \ldots, y_{i k_{i}, t}\right)^{\prime}$. In addition, all country-specific models feature a set of $k_{i}^{*}$ weakly exogenous regressors $y_{i t}^{*}=\left(y_{i 1, t}^{*}, \ldots, y_{i k_{i}, t}^{*}\right)^{\prime}$ constructed as weighted averages of the endogenous variables in other economies,

$$
y_{i j, t}^{*}=\sum_{c=0}^{N} w_{i c} y_{c j, t} \text { for } j=1, \ldots, k_{i}^{*},
$$

where $w_{i c}$ is the weight corresponding to the $j$ th variable of country $c$ in country $i$ 's specification. These weights are typically assumed to be related to bilateral trade exposure or financial linkages. In line with the bulk of the literature on GVAR modelling, we assume that $\sum_{c=0}^{N} w_{i c}=1$ and $w_{i i}=0 .^{1}$

We depart from existing GVAR modelling efforts by specifying country-specific structural VAR models featuring exogenous regressors, time-varying parameters and stochastic volatility, so that

$$
A_{i 0, t} y_{i t}=\sum_{p=1}^{P} B_{i p, t} y_{i t-p}+\sum_{q=0}^{Q} \Lambda_{i q, t} y_{i t-q}^{*}+\varepsilon_{i t},
$$

where

- $A_{i 0, t}$ is a $k_{i} \times k_{i}$ matrix of structural coefficients used to establish contemporaneous relationships between the variables in $y_{i t}$. We assume that $A_{i 0, t}$ is a lower triangular matrix with a diagonal of ones. This choice ensures that the errors of the model are orthogonal to each other by imposing a Cholesky structure on the specification,

- $B_{i p, t}(p=1, \ldots, P)$ is a $k_{i} \times k_{i}$ matrix of coefficients associated with the lagged endogenous variables,

- $\Lambda_{i q, t}(q=0, \ldots, Q)$ denotes a $k_{i} \times k_{i}^{*}$ dimensional coefficient matrix corresponding to the $k_{i}^{*}$ weakly exogenous variables in $y_{i t}^{*}$,

- $\varepsilon_{i t} \sim \mathcal{N}\left(0, D_{i t}\right)$ is a heteroskedastic vector error term with $D_{i t}=\operatorname{diag}\left(\lambda_{i 0, t}, \ldots, \lambda_{i k_{i}, t}\right)$. The assumption of a diagonal $D_{i t}$ simplifies the computational burden of model estimation enormously, since the $k_{i}$ equations can be viewed as separate estimation problems and hence easily parallelized to achieve computational gains, ${ }^{2}$

\footnotetext{
${ }^{1}$ For simplicity, we assume that all variables and countries are linked together by the same set of weights.

${ }^{2}$ The ordering of the variables will be discussed in section 3 and is the same used to identify the structural shocks later on. See the Appendix for further details on the computational challenges involved in obtaining posterior distributions for model quantities of interest.
} 
Stacking the lagged endogenous and weakly exogenous variables in an $m_{i}$-dimensional vector, with $m_{i}=k_{i} P+k_{i}^{*}(Q+1)$,

$$
x_{i t}=\left(y_{i t-1}, \ldots, y_{i t-P}, y_{i t}^{*}, \ldots, y_{i t-Q}^{*}\right)^{\prime}
$$

and storing all coefficients in a $k_{i} \times\left(m_{i} k_{i}\right)$ matrix $\Psi_{i t}$,

$$
\Psi_{i t}=\left(B_{i 1, t}, \ldots, B_{i P, t}, \Lambda_{i 0, t}, \ldots, \Lambda_{i Q, t}\right)^{\prime}
$$

allows us to rewrite equation (2.2) as

$$
A_{i 0, t} y_{i t}=\left(I_{k_{i}} \otimes x_{i t}^{\prime}\right) \operatorname{vec}\left(\Psi_{i t}\right)+\varepsilon_{i t} .
$$

Collecting the elements of $A_{i 0, t}$ which are not zero or unity in a $l_{i}=k_{i}\left(k_{i}-1\right) / 2$-dimensional vector $a_{i 0, t}$, the law of motion of $a_{i 0, t}$ is assumed to be given by

$$
a_{i 0, t}=a_{i 1, t-1}+\epsilon_{i t}, \epsilon_{i t} \sim \mathcal{N}\left(0, V_{i}\right)
$$

where $V_{i}$ is a diagonal variance-covariance matrix with $V_{i}=\operatorname{diag}\left(v_{i 1}^{2}, \ldots, v_{i l_{i}}^{2}\right)$. The diagonal nature stems from the fact that we estimate the model on an equation-by-equation basis, thus effectively disregarding the contemporaneous relationships between parameters in the model. Likewise, we assume that the $K_{i}=k_{i}^{2} m_{i}$ autoregressive coefficients in $\Psi_{i t}$ evolve according to

$$
\operatorname{vec}\left(\Psi_{i t}\right)=\operatorname{vec}\left(\Psi_{i t-1}\right)+\eta_{i t}, \eta_{i t} \sim \mathcal{N}\left(0, S_{i}\right)
$$

with $S_{i}=\operatorname{diag}\left(s_{i 1}^{2}, \ldots, s_{i K_{i}}^{2}\right)$ being a $K_{i} \times K_{i}$ variance-covariance matrix. Finally, the the variances $\lambda_{i l, t}$ are assumed to follow a stationary autoregressive process,

$$
\log \left(\lambda_{i l, t}\right)=\mu_{i l}+\rho_{i l}\left(\log \left(\lambda_{i l, t-1}\right)-\mu_{i l}\right)+v_{i l, t}, v_{i l, t} \sim \mathcal{N}\left(0, \varsigma_{i l}^{2}\right),
$$

where $\mu_{i l}$ denotes the unconditional expectation of the log-volatility, $\rho_{i l}$ the corresponding persistence parameter and $\varsigma_{i l}^{2}$ is the innovation variance of the process.

Some features of the model in equation (2.2) deserve a more detailed explanation. All parameters are allowed to vary over time, which implies that we can explicitly account for changes in domestic and international transmission mechanisms with our specification. Moreover, we also account for heteroskedasticity by making the country-specific variancecovariance matrix of $\varepsilon_{i t}$ time-varying. Our model can thus simultaneously accommodate many features which are commonly observed in macroeconomic and financial time series data. Moreover, the inclusion of weakly exogenous foreign variables accounts for crosscountry linkages and enables us to investigate the propagation of economic shocks across both space and time. Given the marked increase in globalization and the stronger degree of business cycle synchronization experienced globally over the last decades, this is an essential ingredient when modeling the transmission of shocks at the global level.

The set of $N+1$ country specific models can be linked together to yield a global VAR model (Pesaran et al., 2004). Collecting all contemporaneous terms of equation (2.2) and defining a $\left(k_{i}+k_{i}^{*}\right)$-dimensional vector $z_{i t}=\left(y_{i t}^{\prime}, y_{i t}^{*^{\prime}}\right)^{\prime}$, we obtain

$$
C_{i t} z_{i t}=\sum_{\mathfrak{s}=1}^{\mathfrak{S}} L_{i \mathfrak{s}, t} z_{i t-\mathfrak{s}}+\varepsilon_{i t}
$$


with $C_{i t}=\left(A_{i 0, t},-\Lambda_{i 0, t}\right), L_{i s, t}=\left(B_{i p, t}, \Lambda_{i q, t}\right)$ and $\mathfrak{S}=\max (P, Q)$. A global vector $y_{t}=$ $\left(y_{0 t}^{\prime}, \ldots, y_{N t}^{\prime}\right)^{\prime}$ of dimension $k=\sum_{i=0}^{N} k_{i}$ and a corresponding country-specific linkage matrix $W_{i}(i=1, \ldots, N)$ of dimension $\left(k_{i}+k_{i}^{*}\right) \times k$ can be defined so as to rewrite equation (2.9) exclusively in terms of the global vector,

$$
C_{i t} W_{i} y_{t}=\sum_{\mathfrak{s}=1}^{\mathfrak{S}} L_{i \mathfrak{s}, t} W_{i} y_{t-\mathfrak{s}}+\varepsilon_{i t} .
$$

Stacking the equations $N+1$ times yields

$$
G_{t} y_{t}=\sum_{\mathfrak{s}=1}^{\mathfrak{S}} F_{\mathfrak{s} t} y_{t-\mathfrak{s}}+e_{t}
$$

where $G_{t}=\left(\left(C_{0 \mathfrak{s}, t} W_{0}\right)^{\prime}, \ldots,\left(C_{N \mathfrak{s}, t} W_{N}\right)^{\prime}\right), F_{\mathfrak{s} t}=\left(\left(L_{0 \mathfrak{s}, t} W_{0}\right)^{\prime}, \ldots,\left(L_{N \mathfrak{s}, t} W_{N}\right)^{\prime}\right)^{\prime}$ and $e_{t}=\left(\varepsilon_{0 t}^{\prime}, \ldots, \varepsilon_{N t}^{\prime}\right)^{\prime}$. The error term $e_{t}$ is normally distributed with variance-covariance matrix $H_{t}=\operatorname{diag}\left(D_{0 l, t}, \ldots, D_{N l, t}\right)$. Equation (2.11) resembles thus a (very) large VAR model with drifting coefficients which, notwithstanding the problems associated with the high dimensionality of the parameter vector, can be estimated using Bayesian techniques developed to deal with multivariate linear models with time-varying parameters.

\subsection{Bayesian estimation of the TVP-SV-GVAR model}

We use Bayesian methods to carry out inference in the TVP-SV-GVAR model proposed above. Given the risk of overparameterization that is inherent to the specifications used, we rely on Bayesian shrinkage methods to achieve simpler representation of the data. The time-varying nature of the parameters in the model and the presence of the weakly exogenous variables in equation (2.2) present further complications that are tackled in the estimation procedure.

In a Bayesian framework we need to elicit priors on the coefficients in equation (2.5). Crespo Cuaresma et al. (2016) show that prior elicitation at the individual country levels translates into a specific prior structure at the global level, providing additional shrinkage through the trade weights used. We impose a normally distributed prior on $\Psi_{i 0}$, the initial state of $\Psi_{i t}$,

$$
\operatorname{vec}\left(\Psi_{i 0}\right) \sim \mathcal{N}\left(\operatorname{vec}\left(\underline{\Psi}_{i}\right), \underline{V}_{\Psi_{i}}\right),
$$

with $\underline{\Psi}_{i}$ a $k_{i} \times m_{i}$ prior mean matrix and $\underline{V}_{\Psi_{i}}$ a $k_{i} m_{i} \times k_{i} m_{i}$ prior variance-covariance matrix. In addition, we specify a prior for the free parameters of the state equation. We impose a Gamma distributed prior on the elements of the variance-covariance matrix $S_{i}$ in equation (2.7). As noted in Frühwirth-Schnatter and Wagner (2010), this choice proves to be convenient since it does not bound the posterior distribution of $s_{i j}^{2}$ artificially away from zero and provides significantly more shrinkage. Specifically, we assume a prior distribution for $s_{i j}^{2}$ which is given by

$$
s_{i j}^{2} \sim \mathcal{G}\left(\frac{1}{2}, \frac{1}{2 B_{s}}\right), j=1, \ldots, K_{i},
$$


where $B_{s}$ is a scalar hyperparameter controlling the tightness of the prior. The normal prior on $\Psi_{i 0}$ and the set of Gamma priors on $S_{i}$ allow us to achieve shrinkage along two important dimensions. First, the prior on the initial state provides the possibility of shrinking the parameters towards the prior mean which we assume to be zero. Second, the Gamma prior can be specified such that the model is effectively pushed towards a constant coefficient specification a priori, therefore allowing to control the degree of variation of the autoregressive parameters. To see how this prior setup exerts shrinkage on the state variances, note that it is straightforward to show that the Gamma prior on $s_{i j}^{2}$ induces a normal prior on the signed standard deviations $\pm \sqrt{s_{i j}^{2}}$ centered on zero with variance $B_{s}$. Smaller values of $B_{s}$ push the specification a priori towards a constant parameter model.

A set of normal priors are imposed on the initial state of $a_{i 0, t}, a_{i 0,0}$

$$
\operatorname{vec}\left(a_{i 0,0}\right) \sim \mathcal{N}\left(\operatorname{vec}\left(\underline{a}_{i}\right), \underline{V}_{a_{i}}\right),
$$

where $\underline{a}_{i}$ and $\underline{V}_{a_{i}}$ denote the prior mean and prior variance covariance matrices of the initial state. Similarly to the prior on $S_{i}$, we impose a set of Gamma priors on the elements of $V_{i}$

$$
v_{i r}^{2} \sim \mathcal{G}\left(\frac{1}{2}, \frac{1}{2 B_{v}}\right), r=1, \ldots, l_{i} .
$$

Here, we let $B_{v}$ denote the shrinkage hyperparameter used to penalize variation in the covariances of the model.

Finally, we use the prior setup proposed in Kastner and Frühwirth-Schnatter (2013) and subsequently used in Huber (2016) on the coefficients of the log-volatility process in equation (2.8). A normal prior is imposed on $\mu_{i l}\left(l=1, \ldots, k_{i}\right)$ with mean $\underline{\mu}_{i}$ and variance $\underline{V}_{\mu_{i}}$

$$
\mu_{i l} \sim \mathcal{N}\left(\underline{\mu}_{i}, \underline{V}_{\mu_{i}}\right)
$$

For the persistence parameter $\rho_{i l}$, we elicit a beta prior

$$
\frac{\rho_{i l}+1}{2} \sim \operatorname{Beta}\left(a_{0}, b_{0}\right),
$$

which implies

$$
\begin{aligned}
E\left(\rho_{i l}\right) & =\frac{2 a_{0}}{a_{0}+b_{0}}-1, \\
\operatorname{Var}\left(\rho_{i l}\right) & =\frac{4 a_{0} b_{0}}{\left(a_{0}+b_{0}\right)^{2}\left(a_{0}+b_{0}+1\right)} .
\end{aligned}
$$

For typical data sets arising in macroeconomics, the exact choice of the hyperparameters $a_{0}$ and $b_{0}$ in equation (2.17) is quite influential, since data do not tend to be very informative about the degree of persistence of log-volatilities.

We impose a non-conjugate gamma prior for $\varsigma_{i j}^{2},\left(j=1, \ldots, k_{i}\right)$,

$$
\varsigma_{i j}^{2} \sim \mathcal{G}\left(\frac{1}{2}, \frac{1}{2 B_{\varsigma}}\right)
$$


Mirroring the properties of the prior used for the other state equations, this choice does not bound $\varsigma_{i l}^{2}$ away from zero, thus providing more shrinkage than standard typical conjugate inverted gamma priors do. Moreover, such a prior setting can improve sampling efficiency considerably (Kastner and Frühwirth-Schnatter, 2013).

Using the prior setting described above, a Markov chain Monte Carlo (MCMC) algorithm to draw samples from the (country-specific) parameter posterior distribution can be designed. Let us denote the full history of the time-varying elements in equation (2.9) up to time $T$ as

$$
\begin{aligned}
\operatorname{vec}\left(\Psi_{i}^{T}\right) & =\left(\operatorname{vec}\left(\Psi_{i 1}\right)^{\prime}, \ldots, \operatorname{vec}\left(\Psi_{i T}\right)^{\prime}\right)^{\prime}, \\
a_{i}^{T} & =\left(a_{i 1}^{\prime}, \ldots, a_{i T}^{\prime}\right)^{\prime} \\
\lambda_{i}^{T} & =\left(\lambda_{i 1}, \ldots, \lambda_{i T}\right)^{\prime} .
\end{aligned}
$$

The MCMC algorithm consists of the following blocks

- $\operatorname{vec}\left(\Psi_{i}^{T}\right)$ and $a_{i}^{T}$ are sampled through the well known algorithm provided in Carter and Kohn (1994) and Frühwirth-Schnatter (1994).

- Conditional on $\operatorname{vec}\left(\Psi_{i}^{T}\right)$ and $a_{i}^{T}$, the variances in equation (2.6) and equation (2.7) can be sampled from a generalized inverse Gaussian distribution, ${ }^{3}$ i.e.

$$
\begin{aligned}
s_{i j}^{2} \mid \operatorname{vec}\left(\Psi_{i}^{T}\right) & \sim \mathcal{G} \mathcal{I} \mathcal{G}\left(\frac{1}{2}-\frac{T}{2}, \sum_{t=1}^{T}\left(\Psi_{i j, t}-\Psi_{i j, t-1}\right)^{2}, \frac{1}{2 B_{s}}\right), \\
v_{i j}^{2} \mid a_{i}^{T} & \sim \mathcal{G} \mathcal{I} \mathcal{G}\left(\frac{1}{2}-\frac{T}{2}, \sum_{t=1}^{T}\left(a_{i j, t}-a_{i j, t-1}\right)^{2}, \frac{1}{2 B_{v}}\right),
\end{aligned}
$$

with $\Psi_{i j, t}$ denoting the $j$ th element of the $\operatorname{vec}\left(\Psi_{i t}\right)$.

- The history of log volatilities is sampled using the algorithm outlined in Kastner and Frühwirth-Schnatter (2013). ${ }^{4}$

\section{Data, model specification and prior implementation}

This section introduces the data and the priors placed on the parameters of the model framework. We extend the dataset used in Dees et al. (2007a,b) with respect to both variable coverage and time span. In our analysis we use quarterly data for 36 countries spanning the period from 1979:Q2 to 2013:Q4. The countries covered in our sample are shown in Table 1.

[Table 1 about here.]

\footnotetext{
${ }^{3}$ The corresponding proof can be found in the Appendix.

${ }^{4}$ Further details of the sampling algorithm by Kastner and Frühwirth-Schnatter (2013) can be found in the Appendix.
} 
The country-specific TVP-VAR-SV models include real GDP growth $(\Delta y)$, the log-difference of the consumer price level $(\Delta p)$, the log-difference of the real exchange rate $(\Delta e)$ vis-á-vis the US dollar, short-term interest rates $(i)$ and the term spread, constructed as the difference between long-term and short-term interest rates $(s)$. Note that not all variables are available for each of the countries we consider in this study. However, with the exception of long-term interest rates (that are used to calculate the term-spread), the coverage of all variables is above $80 \%$.

The vector of domestic variables for a typical country $i$ is given by

$$
\boldsymbol{x}_{i t}=\left(\Delta y_{i t}, \Delta p_{i t}, \Delta e_{i t}, i_{i t}, s_{i t}\right)^{\prime} .
$$

We follow the bulk of the literature on GVAR modelling by including oil prices (poil) as a global control variable. With the exception of the bilateral real exchange rate, we construct foreign counterparts for all domestic variables. The weights to calculate foreign variables are based on average bilateral annual trade flows in the period from 1980 to $2003 .{ }^{5}$ For a typical country $i$ the set of weakly exogenous and global control variables comprises

$$
\boldsymbol{x}_{i t}^{*}=\left(\Delta y_{i t}^{*}, \Delta p_{i t}^{*}, i_{i t}^{*}, s_{i t}^{*}, \Delta p o i l\right)^{\prime} .
$$

The US model, which we normalize to correspond to $i=0$, deviates from the other country specifications in that the oil price is determined within that country model and the trade weighted real exchange rate $\left(\Delta e^{*}\right)$ is included as an additional control variable, so that its vectors of endogenous and weakly exogenous variables are given by

$$
\begin{aligned}
& \boldsymbol{x}_{0 t}=\left(\Delta \text { poil }_{t}, \Delta y_{0 t}, \Delta p_{0 t}, i_{0 t}, s_{0 t}\right)^{\prime} \\
& \boldsymbol{x}_{0 t}^{*}=\left(\Delta y_{0 t}^{*}, \Delta p_{0 t}^{*}, \Delta e_{0 t}^{*}, i_{0 t}^{*}, s_{0 t}^{*}\right)^{\prime} .
\end{aligned}
$$

For identification of the US monetary policy shock we rely on the recursive identification designed proposed - among others - in Christiano et al. (2005). For that purpose, we order the block of variables that do not react instantaneously to a monetary policy shock first $\left(\Delta\right.$ poil $\left._{t}, \Delta y_{0 t}, \Delta p_{0 t}\right)$, followed by the policy instrument $\left(i_{0 t}\right)$ and a block that reacts immediately if the monetary policy shock hits the economy $\left(s_{0 t}\right)$ (Christiano et al., 1999). This ensures identification of the monetary policy shock. All results considered below are based on generalized structural impulse response functions (see Dees et al., 2007a) that aim to identify the structural responses to the shock of interest while integrating out other shocks. This yields generalized impulse responses to shocks that are not explicitly identified and structural responses to the US monetary policy shock. For all countries considered, we set the lag length of endogenous and weakly exogenous variables equal to one. Given the relatively short period

\footnotetext{
${ }^{5}$ Note that recent contributions (Eickmeier and $\mathrm{Ng}, 2015$; Dovern and van Roye, 2014) suggest using financial data to compute foreign variables related to the financial side of the economy (e.g., interest rates or credit volumes). Since our data sample starts in the early 1980s, reliable data on financial flows - such as portfolio flows or foreign direct investment - are not available. See the Appendix of Feldkircher and Huber (2016) for the results of a sensitivity analysis with respect to the choice of weights in Bayesian GVAR specifications in the framework of models with fixed parameters.
} 
spanned by our sample, the high parametrization of the model and the quarterly frequency of the data, this seems to be a reasonable choice. ${ }^{6}$

Before proceeding to the empirical results, we discuss the specific choices of the hyperparameters needed to construct our prior distributions. Since the GVAR comprises $N+1$ countries, each country could be endowed with a country-specific set of hyperparameters. We simplify the elicitation of the prior by imposing equal hyperparameters across countries. For the prior over the initial state $\Psi_{i 0}$, we set $\operatorname{vec}\left(\underline{\Psi}_{i}\right)=0$ and $\underline{V}_{\Psi_{i}}=10 I_{k_{i} m_{i}}$. Similarly we set $\operatorname{vec}\left(\underline{a}_{j}\right)=0$ and $\underline{V}_{a_{i}}$ equal to a diagonal matrix with 10 on its main diagonal. This setup renders the prior on the initial conditions fairly uninformative and proves not to be influential in the empirical application.

The prior on the innovation variances of the state equations in equation (2.6) and equation (2.7) is set such that $B_{v}=B_{s}=0.1$. This choice is highly influential in practice, so we have thus performed extensive robustness checks with respect to those hyperparameters. In contrast to Primiceri (2005), who elicits the prior on the variance of the state innovations using a pre-sample of data, we evaluate different hyperparameters on a grid of values, ranging from values which translate into a much tighter prior than Primiceri (2005)'s setup to a specification with a prior which is quite loose. Given that we are interested in allowing the data to be as informative as possible with respect to the drifting behavior of the coefficients, we strongly favor hyperparameters that are loose. We still impose enough discipline on the parameter dynamics such that the resulting posterior quantities do not show explosive behavior. The grid of parameter values we evaluate is given by $(0.001,0.01,0.1,0.5,1,4)$ where we pick 0.1 as our reference value for both $B_{v}$ and $B_{s}$. Higher values typically lead to posterior draws which are excessively unstable, resulting in implausible impulse-responses.

Finally, the prior on the mean of the log-volatility equation is set such that $\mu_{i}=0$ and $\underline{V}_{\mu_{i}}=10$, which is uninformative given the scale of our data. For the autoregressive parameter $\rho_{i l}$ we set $a_{0}$ and $b_{0}$ equal to 25 and 1.5, respectively. This prior places a lot of mass on high persistence regions of the parameter space. Since the data is usually not informative about the autoregressive parameter on a latent factor, the corresponding posterior distribution can be significantly shaped by this choice. A sensitivity analysis using hyperparameters that place more prior mass on stationary regions of $\rho_{i l}$ leads to qualitatively similar results to those presented in this section. The last piece missing is the prior on $\varsigma_{i l}$, where we only have to elicit $B_{\sigma}$, which is set equal to unity.

We compute all relevant quantities by performing Monte Carlo integration by drawing 1,500 samples from a total chain of 30,000 draws, where the first 15,000 draws are discarded. Standard diagnostic checks indicate convergence to the stationary distribution, with inefficiency factors for the autoregressive coefficients and volatilities well below 20 for most country models. ${ }^{7}$

\footnotetext{
${ }^{6}$ We also corrected for outliers in countries that witnessed extraordinarily strong crisis-induced movements in some of the variables contained in our data. We accounted for these potentially influential observations by smoothing the relevant time series after defining outliers as those observations that exceed 1.5 times the interquartile range in absolute value.

${ }^{7}$ Further information on the convergence properties of the sampler for our empirical application can be found in the Appendix.
} 


\section{The international dimension of US monetary policy}

Making use of the estimated TVP-SV-GVAR, in this section we investigate in a first step how US monetary policy affects international output, prices, short-term interest rates and exchange rates. In a second step we ask the reverse question and analyze whether and how US monetary policy responds to four typical foreign shocks: an increase in foreign interest rates, a negative shock to foreign real GDP growth, an increase in foreign inflation and an appreciation of the US dollar. For both sets of experiments, our analysis draws explicit attention to changes in the reactions over time.

\subsection{Does the global economy respond to US monetary policy shocks?}

First, we analyze international effects of US monetary policy using the newly developed TVPSV-GVAR model. In contrast to existing literature, we are able to assess whether spillovers have changed over time and whether there is evidence for significant cross-country differences. Hitherto the empirical literature has found significant effects of US monetary policy on global output. Most studies assessing the effects of macroeconomic shocks in the US economy on the world either use stylized linear two-country vector autoregressions (see for example Kim, 2001; Canova, 2005) or systems of country-specific models. Both approaches have been mostly confined to linear models with fixed parameters and are thus not able to track changes in the transmission channel or the external environment. Canova (2005), for example, finds large and significant output responses to US monetary policy shocks in Latin America. In line with Kim (2001), the transmission tends to be driven by the strong response of domestic interest rates to US monetary expansions rather than by the trade balance. Ehrmann and Fratzscher (2009) show that US monetary policy shocks impact strongly on short-term interest rates and ultimately on equity markets in a large number of economies. Several recent contributions draw on the framework put forth in Pesaran et al. (2004) and use a global system of vector autoregressions to investigate the propagation of different monetary and fiscal policy shocks across the globe (see for instance Dees et al., 2007a; 2010; Feldkircher and Huber, 2016). Employing this framework and using a Bayesian set-up, Feldkircher and Huber (2016) find significant and rather persistent spillovers from US monetary policy shocks on international output. Examining conditional forecasts of different future policy paths for the federal funds rate, Feldkircher et al. (2015) find strong direct spillover effects for output in emerging economies, while second-round effects play a more prominent role in advanced economies.

We investigate the international responses to an unexpected US monetary policy tightening normalized to 100 basis points (bp) throughout the sample period. While the shock on impact is fixed to $100 \mathrm{bp}$ for the US, spillovers generated by the shock are allowed to vary if macroeconomic relationships or residual variances change over time. A hypothetical monetary policy shock during the period of the global financial crisis, when economic and financial conditions are weak and macroeconomic uncertainty is high, might impact differently on international output than during tranquil times, warranting a time-varying parameter framework. The results are summarized in Figures 1 to 4, which show the posterior mean of the corresponding (cumulative) impulse response for selected countries, along 25\% and 75\% 
credible sets of the cross-country means (gray shaded regions). These can be interpreted as the uncertainty surrounding the impulse responses of a typical country from a given region. Responses are shown over the whole sample period and for the one and eight quarter forecast horizon.

Figure 1 shows the cumulative response of output to the monetary policy shock originated in the US. The estimated effects for the US economy itself are in line with the empirical literature on US monetary policy (see, e.g., Christiano et al., 1999; Coibion, 2012). In most economies, including the US itself, output contracts and responses tend to be rather persistent, corroborating the findings by Feldkircher and Huber (2016), who use a linear, time-invariant version of the Bayesian GVAR model. Looking at different world regions, most responses are very homogeneous and fall inside the credible sets spanned by the respective cross-country means. Canada shows a very pronounced negative response that is even stronger than the domestic reaction of output in the US itself. Also for Germany and Japan, spillovers of the US monetary policy shock are strong. Countries with positive impact responses and that deviate from their regional peers include Australia, Indonesia, Mexico and Spain. While in the medium term, Australia and Indonesia seem rather isolated from the shock with responses hovering around zero, the response in Mexico and Spain becomes negative and thus in line with its regional peers. Considerable time variation is evident from the graphs. More specifically, from the mid-1990s onward most economies show a downward-trending medium-term response, which reaches a trough around the episode of the global financial crisis, after which responses become less pronounced again. Taken at face value, this finding reveals stronger effects on international output in the most recent part of our sample as compared to earlier periods.

[Figure 1 about here.]

Figure 2 shows the effects on international prices. Responses in other developed and Western European economies are very homogeneous. They are mostly negative in the short-run and peter out very quickly. By contrast, there is considerably more variation across countries in emerging Asia and Latin America. In emerging Asia, the monetary policy tightening tends to trigger negative reactions of prices on impact, while responses in the medium-term are close to zero. Showing an increase of prices, Indonesia seems an exception in the region. Impact responses in Latin America tend to be positive and pronounced for all countries but Argentina. Responses are rather persistent, especially for Chile and Peru (positive) and Argentina (negative). Modeling changes in parameters and variances seems particularly important when assessing spillovers for emerging markets, which show more pronounced reactions during the 2000s and smaller responses in the aftermath of the global financial crisis.

[Figure 2 about here.]

Figure 3 shows the non-cumulative response of interest rates with respect to the monetary policy shock. Using a simpler specification than that employed here, comovements of interest rates have been identified as an important transmission channel of macroeconomic shocks in Feldkircher and Huber (2016). Indeed, almost all countries follow the rate hike in the 
US in the short-run. After eight quarters, the direct effect on domestic interest rates has practically disappeared in most countries. Countries that show a particularly pronounced behavior include Canada, Great Britain, India and Latin American economies. This implies that the interest rate reaction is large in countries that share strong economic ties with the US and fast growing emerging economies, that have been also hit in the past strongly when the Fed announced interest rate changes (see, e.g., the taper tantrum episode in mid-2013). The importance of the financial channel in transmitting US shocks for Latin America has also been shown in Canova (2005). In line with results on international prices, most countries tend to show stronger medium-term responses during the mid-1990s to mid-2000s and comparably smaller responses in the most recent period of the sample.

[Figure 3 about here.]

Next, Figure 4 shows the responses of the real exchange rate vis-á-vis the US dollar. As expected, responses tend to be positive on impact indicating a real appreciation of the US dollar as a consequence of the stronger increase in domestic interest rates. Naturally, advanced countries that are strongly linked to the US in economic terms respond more strongly to the monetary policy shock. These include Australia, Canada and New Zealand, and to a lesser extent Great Britain. Among emerging economies, currencies that weaken against the US dollar include Korea, Brazil and Chile. For all these currency pairs there is also considerable evidence of time variation. The depreciation of the domestic currency is more pronounced in response to a hypothetical monetary policy shock hitting the economies in the 2000s than in the early part of our sample. Moreover, responses became smaller in the aftermath of the global financial crisis for all currencies.

[Figure 4 about here.]

Figures 5 to 6 depict the residual variance estimates for the variables discussed above. Our modeling framework provides also explicit inference on the dynamics of macroeconomic volatility. As an example, Figure 5 plots the volatility of GDP growth, mean-standardized in order to facilitate cross-country comparison. A decline in the volatility of GDP growth in Western Europe and other developed economies can be observed until the middle of the 2000s, a development which is in line with the dampening of real fluctuations corresponding to the Great Moderation period. After 2007, a sharp increase in output growth volatility due to the outbreak of the global financial crisis can be seen, followed by a gradual return to lower volatility more recently. Economies in Latin America and Asia witnessed episodes of increased volatility of GDP growth also during crises in the 1980's and 1990's, respectively. In some emerging economies (Thailand, Korea and Argentina) volatility following the global financial crisis increased sharply. Volatility spikes in other variables occur more frequently in emerging Asia and Latin American economies, while they are less frequent in advanced economies. The timing of the spikes also differs. For example, high volatility attached to inflation spikes is a common phenomenon in the early 1980s in Latin America, when some countries witnessed periods of hyperinflation. On the other hand, residual variance increases sharply in advanced countries around the period of the global financial crisis, which was 
marked by deflationary pressures. Naturally, among all variables considered, volatility of real exchange rates exhibit the highest variability for all regions, including advanced economies. Overall, our model framework correctly identifies periods of heightened uncertainty such as the Asian and the global financial crisis, yielding further confidence to our results.

[Figure 5 about here.]

[Figure 6 about here.]

Summing up, we find that a US monetary tightening tends to decrease international output with effects which are visible even after eight quarters, while prices tend to decrease in the short-term but adjust quickly thereafter. International interest rates tend to follow the US rate hike and most currencies weaken against the US dollar in response to the tightening. In the medium-term, responses tend to be more pronounced for those countries that share strong economic links with the US and for emerging economies. We find relevant time variation in international spillovers. With the exception of output, most responses tend to be large during the mid-1990s to mid-2000s, while effects tend to be smaller in the most recent period of the sample. Output responses were most pronounced during the period of the global financial crisis and less so afterwards. The residual variance component of our model correctly identifies known periods of heightened uncertainty in the past.

\subsection{Does the US Fed respond to international shocks?}

Typically, the policy rule of the US Fed is modeled as a linear function of purely domestic quantities (Christiano et al., 1999). For instance, the Taylor rule (Taylor, 1993) postulates that the Fed sets the policy rate according to a simple linear function of inflation expectations, the output gap and possibly the effective exchange rate (Taylor, 2002; Clarida et al., 1998). It is thus theoretically ruled out that the Fed reacts to international economic developments beyond the spillovers which are directly reflected in domestic US macroeconomic variables. In addition, the assumption of a linear monetary policy reaction function implies that the central bank conducts monetary policy based on elasticities which are independent from the prevailing state of the economy, i.e., the reaction function is the same in boom and bust phases.

To provide further insights on the theoretical relationship between the preferences of the central banks and global macroeconomic developments, we use a simplified variant of the model outlined in Rudebusch and Svensson (1999) and Bernanke et al. (2005). We assume that the economy is described by the following set of equations:

$$
\begin{aligned}
\Delta p_{t} & =\delta \Delta p_{t-1}+\kappa\left(y_{t-1}-\bar{y}_{t-1}\right)+\mathfrak{s}_{t}, \\
y_{t} & =\phi y_{t-1}-\psi\left(i_{t-1}-\Delta p_{t-1}\right)+\theta \chi_{t}+d_{t}, \\
\chi_{t} & =\omega y_{t}^{*}-\alpha y_{t},
\end{aligned}
$$

where $\Delta p_{t}$ and $y_{t}$ denote the rate of inflation and current output, respectively, $\bar{y}_{t}$ denotes potential output and $\mathfrak{s}_{t}$ is a serially correlated cost-push shock. The policy rate controlled by the 
monetary policy authority is denoted by $i_{t}$ and $y_{t}^{*}$ denotes foreign output. The aggregate demand equation given by (4.2) contains a net exports component, $\chi_{t}$, which is in turn assumed to depend on foreign and domestic output. Assuming a zero inflation target, the central bank sets the policy rate according to

$$
i_{t}=\beta \Delta p_{t}+\gamma\left(y_{t}-\bar{y}_{t}\right)+\epsilon_{t}
$$

Here, $\epsilon_{t}$ denotes a zero mean monetary policy shock with constant variance. Plugging equation (4.3) into equation (4.2) and solving for $y_{t}$ yields

$$
y_{t}=\frac{1}{1+\alpha}\left[\phi y_{t-1}-\psi\left(i_{t-1}-\Delta p_{t-1}\right)+\theta \omega y_{t}^{*}+d_{t}\right] \text {. }
$$

By substituting equation (4.5) in equation (4.4), we relate foreign output with the policy rate through an augmented Taylor rule equation,

$$
i_{t}=\beta \pi_{t}+\tilde{\psi} y_{t-1}-\tilde{\psi}\left(i_{t-1}-\Delta p_{t-1}\right)+\tilde{\omega} y_{t}^{*}+\tilde{\gamma} d_{t}-\gamma \bar{y}_{t}+\epsilon_{t},
$$

with $\tilde{\psi}=\frac{\gamma \psi}{1+\alpha}, \tilde{\psi}=\frac{\gamma \psi}{1+\alpha}, \tilde{\omega}=\frac{\gamma \theta \omega}{1+\alpha}$ and $\tilde{\gamma}=\frac{\gamma}{1+\alpha}$. Assuming $\alpha=0$ and $\omega=0$ leads to the model of Bernanke et al. (2005). Note that equation (4.6) implies that $\frac{\partial i_{t}}{\partial y_{t}^{*}}=\tilde{\omega}$, which is greater than zero if $\gamma, \theta, \omega, \alpha>0$, a set of assumptions which is routinely assumed to hold in this type of model. If $\tilde{\omega}>0$, the central bank increases its policy rate as a response to a positive international output shock. This shows that even if the central bank does not explicitly consider international output in its reaction function, there are indirect channels that lead to global developments playing a role in domestic monetary policy. It is straightforward to show that the model given by equations (4.1) - (4.6) is a restricted variant of equation (2.2), where only weakly exogenous output is included and the parameters are assumed to be constant over time. $^{8}$

In practice, the structural parameters embodied in the coefficients of equation (4.6) can be thought of as changing over time and we can relax the assumption that international output is the only variable affecting domestic monetary policy by assuming that the policy instrument is set according to

$$
i_{t}=\mathfrak{f}_{t}\left(\Omega_{t}\right)+\epsilon_{t},
$$

where $\mathfrak{f}_{t}\left(\Omega_{t}\right)$ is a potentially non-linear function of the information set of the central bank up to time $t\left(\Omega_{t}\right)$. Relating equation (4.7) to the GVAR model outlined in Section 2 implies that $\Omega_{t}$ now may include information on international output, interest rates, prices, exchange rates and term spreads. This allows us to investigate the behavior of US monetary policy when facing shocks to the aforementioned international quantities.

To assess the international dimension of US monetary policy we perform a set of simple counterfactual exercises by estimating the response of US interest rates to four distinct regional shocks: ${ }^{9}$

\footnotetext{
${ }^{8}$ It is straightforward to extend the theoretical framework and incorporate further international macroeconomic variables such as international price movements or changes in foreign interest rates. For the sake of brevity and since the model presented here is purely exemplary, we exclusively consider output as a foreign variable.

${ }^{9}$ We do not compute a regional shock for the group of "other developed economies" since this group is rather heterogeneous and from an economic perspective it seems unlikely that these economies are hit by similar regional shocks.
} 
1. an average 100 bp decrease in short-term interest rates in Western Europe, Asia and Latin America,

2. an increase in inflation by around one percentage point, on average, in Western Europe, Asia and Latin America,

3. a reduction of output growth by around one percentage point, on average, in Western Europe, Asia and Latin America,

4. a one percent real appreciation of the US dollar against currencies in Western Europe, Asia and Latin America.

To assess the impact of these shocks on US short-term interest rates we rely on generalized impulse response functions (GIRFs) as proposed in Pesaran and Shin (1998). GIRFs are appealing since they are insensitive to the ordering of the variables in the system, while the shocks in general remain (weakly) correlated which strictly speaking prohibits a structural and economic interpretation. In practice, however, residual correlation is weak, especially when using a GVAR approach, since the weakly exogenous variables absorb a lot of the existing correlation. As an alternative, we impose zero-impact restrictions akin to the identifying assumptions used to recover the US monetary policy shock. More specifically, we assume the following ordering: $\boldsymbol{x}_{i t}=\left(\Delta y_{i t}, \Delta p_{i t}, \Delta e_{i t}, i_{i t}, s_{i t}\right)^{\prime}$. This allows us to give the first shock mentioned above a structural interpretation, namely that of a contractionary regional monetary policy shock.

Figure 7 depicts the posterior median of the response of the US short-term interest rate with respect to the different shocks described above. In addition, Table 2 presents the posterior estimates of the responses of the US short-term interest rates, averaged across different periods corresponding to the mandates of the Fed's chairmen Volcker, Bernanke and Greenspan.

[Table 2 about here.]

Several findings are worth emphasizing. First, looking at the median responses to an increase in regional short-term interest rates, we find that US short-term rates tend to increase after one quarter when the shock originates in Western Europe and tend to decrease when the shock comes from emerging economies in Asia and Latin America. At the eight quarter forecast horizon, the response of US short-term rates is negative to all three regional shocks. That is, if short-term rates are raised abroad the Fed tends to cut domestic rates probably to stabilize output and to compensate for the shortfall in foreign demand. This is in contrast to our results on spillovers generated by US monetary policy shocks, where international shortterm rates tend to follow the US rate hike even in the medium-term. Concentrating on the variation of responses over time, the effects on interest rates have increased, probably on the back of stronger financial globalization. With the exception of Latin America, effects are tightly estimated for almost all periods. Wide credible sets for Latin American shocks might be driven by the fact that many countries in that region have historically fixed their currency in one way or the other to the US dollar and thus would rather follow than lead US rate changes. 
Considering an increase in regional inflation next, the posterior median indicates that domestic interest rates in the US tend to increase in the short-run and significantly so when the shocks originate in Western Europe or Asia. After eight quarters, the Fed cut rates to enhance domestic demand and to compensate for the shortfall in foreign demand. Effects are tightly estimated in the short-run when shocks originate in Western Europe and even in the medium-term when the shock origin is Asia. Responses to inflation increases originating in Latin America are accompanied by wide credible sets for all time periods considered.

Next we look at responses to a fall in foreign real GDP growth. Here, and in contrast to responses to shocks to regional inflation, estimates based on the posterior median point to an immediate rate decrease in the US. This might be driven by contained international prices and spillovers which should put downward pressure on US prices and thus make room for a rate decrease. In the medium-term, interest rates continue to decrease to spur domestic demand. Responses are tightly estimated for all three time periods and regardless of where the shock originates.

Last we look how US rates respond to a regional strengthening of the US dollar. Here, the immediate response of US short-term rates depends strongly on where the shock comes from. For example, if the US dollar appreciates against a basket of Western European and Latin American economies, short-term interest rates tick up in the short-run. By contrast, if the shock originates in Asia, the Fed responds by lowering short-term rates. In the medium term, short-term rates decrease in response to all three shocks, but credible sets are wide for all regions but Latin America in the two most recent periods of our sample. Here, and with the exception of the Volcker regime, interest rates medium-term responses are tightly estimated and negative.

As a robustness check we also obtained posterior quantities based on a recursive ordering in Table B.1. ${ }^{10}$ In line with results based on generalized impulse response functions, we find tightly estimated responses to a foreign monetary policy shock / increase in regional shortterm interest rates with the Fed decreasing rates in the medium-term. This emphasizes the important role of the financial / interest rate channel, not only when shocks originate in the US - as discussed in the previous section - but also for US monetary policy as a recipient of spillovers. Other shocks tend to produce qualitatively similar results in terms of size and movement of US short-term rates. However, when identifying the foreign shocks recursively, credible sets tend to be wider, which might indicate that the recursive identification scheme is not well suited to recover shocks besides the monetary policy shock.

Summing up, we find significant responses of US short-term interest rates to foreign monetary policy / short-term interest rate shocks and to contractionary foreign real GDP growth shocks for all three regions considered. Responses to other shocks depend on their origin. In the medium term, US short-term rates decrease when either foreign monetary policy is tightened or foreign real GDP growth decreases. This drives up domestic economic growth thereby compensating for the fall in foreign demand. Looking at the three regions of origin of potential shocks, most tightly estimated responses correspond to shocks from Asia, which includes China. Here, US rates also respond to an exchange rate shock in the short-run and to an inflation shock in the medium-term.

\footnotetext{
${ }^{10}$ Detailed numerical results are presented in the Appendix.
} 
[Figure 7 about here.]

\section{Closing remarks}

This paper analyzes the interlinkages of US monetary policy and the global economy. For that purpose we develop a time-varying parameter global vector autoregression with stochastic volatility (TVP-SV-GVAR). We use this framework to assess spillovers originating from disturbances to US monetary policy on a country-by-country basis taking explicitly into account that the extent of spillovers might have changed over time. Finally, we ask the reverse question: Does the US Fed respond to international shocks? If yes, have these responses changed over time? This part of the analysis is carried out by simulating four regional shocks and investigating the subsequent response of the US policy rate.

We find significant international effects caused by an unexpected tightening of US policy rates. In general, a US monetary policy contraction tends to decrease global output and this response is more persistent than transitory, a result which is in line with Feldkircher and Huber (2016). Following the response of the US, global inflation rates tend to decrease immediately and adjust quickly in the medium term. Also global short-term interest rates tend to follow their US counterparts increasing in response to the US rate hike. Naturally, the US tightening causes a nominal appreciation of the US dollar. This appreciation, however, carries also over in real terms. These results describe global trends in our sample. We observe, however, a great deal of cross-country heterogeneity regarding the spillovers. In general, our analysis reveals stronger responses for those countries that have been hit severely during the "taper tantrum" episode in the summer of 2013 during which markets believed that the Fed would tighten its monetary policy stance (e.g., Brazil, India, Indonesia, Peru). On top of that, countries that share either pronounced trade links with the US economy (e.g., Canada, Great Britain, Mexico) or industrialized economies that are heavily integrated with the world economy (e.g., Japan, Germany) tend to show stronger responses to an unexpected US rate hike. These results are broadly in line with Feldkircher et al. (2015), who use a simpler version of the GVAR model.

Second, we find evidence for a changing transmission of monetary policy shocks at the global level over time. More specifically, most responses are more pronounced during the mid-1990s to mid-2000s, while effects tend to be smaller in the most recent period of the sample. This holds true for effects on international inflation, short-term interest rates and exchange rates. By contrast, the international effects of US monetary policy on output are strongly shaped by the economic developments during the most recent part of our sample. Effects are most pronounced during the global financial crisis, when uncertainty was elevated and a boost to stimulate the economy might have been most effective. In the aftermath of the crisis, international spillover effects are comparably smaller but still more pronounced than in the early part of our sample, when financial globalization was less developed.

Last, we examine whether US monetary policy responds to foreign regional macroeconomic shocks. Depending on the nature of the foreign shock we find significant responses of US short-term rates. More specifically, if foreign policy rates are unexpectedly tightened or foreign real GDP growth decelerates, US rates decrease in response. This boosts economic 
growth in the US and compensates for the shortfall in foreign demand. We also find that the response of US rates to foreign monetary policy shocks has increased over time, probably due to increased financial globalization. We do not find such compelling evidence in response to a shock to foreign inflation or a weakening of foreign currencies against the US dollar. An exception to this are shocks that originate from the Asian region which includes China. Here, almost all shocks trigger a significant response on US short-term interest rates emphasizing the important role this region plays for the US economy. 


\section{References}

Bernanke BS, Boivin J and Eliasz P (2005) Measuring the Effects of Monetary Policy: A FactorAugmented Vector Autoregressive (FAVAR) Approach. The Quarterly Journal of Economics $120,387-422$

Bloom N (2009) The Impact of Uncertainty Shocks. Econometrica 77(3), 623-685

Canova F (2005) The transmission of US shocks to Latin America. Journal of Applied Econometrics 20(2), 229-251

Carter CK and Kohn R (1994) On Gibbs sampling for state space models. Biometrika 81(3), $541-553$

Christiano LJ, Eichenbaum M and Evans CL (1999) Monetary policy shocks: What have we learned and to what end? Handbook of Macroeconomics 1, 65-148

Christiano LJ, Eichenbaum M and Evans CL (2005) Nominal rigidities and the dynamic effects of a shock to monetary policy. Journal of Political Economy 113(1), 1-45

Clarida R, Galı J and Gertler M (1998) Monetary policy rules in practice: some international evidence. european economic review 42(6), 1033-1067

Coibion O (2012) Are the Effects of Monetary Policy Shocks Big or Small? American Economic Journal: Macroeconomics 4(2), 1-32

Crespo Cuaresma J, Feldkircher M and Huber F (2016) Forecasting with Global Vector Autoregressive Models: A Bayesian Approach. Journal of Applied Econometrics, forthcoming

Dees S, di Mauro F, Pesaran HM and Smith LV (2007a) Exploring the international linkages of the euro area: a global VAR analysis. Journal of Applied Econometrics 22(1)

Dees S, Holly S, Pesaran HM and Smith VL (2007b) Long Run Macroeconomic Relations in the Global Economy. Economics - The Open-Access, Open-Assessment E-Journal 1(3), 1-20

Dees S, Pesaran H, Smith V and Smith RP (2010) Supply, demand and monetary policy shocks in a multi-country New Keynesian Model. Working Paper Series 1239, European Central Bank

Dovern $\mathrm{J}$ and van Roye B (2014) International transmission and business-cycle effects of financial stress. Journal of Financial Stability 13(0), 1 - 17

Ehrmann M and Fratzscher M (2009) Global Financial Transmission of Monetary Policy Shocks. Oxford Bulletin of Economics and Statistics 71(6), 739-759

Eickmeier S and Ng T (2015) How do US credit supply shocks propagate internationally? A GVAR approach. European Economic Review 74, 128 - 145

Feldkircher M and Huber F (2016) The international transmission of US shocks - Evidence from Bayesian global vector autoregressions. European Economic Review 81, 167 - 188

Feldkircher M, Moder I and Huber F (2015) Towards a New Normal - How Different Paths of US Monetary Policy affect the World Economy. Economic Notes 44(3), 409-418

Fernández-Villaverde J, Guerró-Quintana P, Rubio-Ramírez JF and Uribe M (2011) Risk Matters: The Real Effects of Volatility Shocks. American Economic Review 101(6), 2530-61

Frühwirth-Schnatter S (1994) Data augmentation and dynamic linear models. Journal of time series analysis 15(2), 183-202

Frühwirth-Schnatter S and Wagner H (2010) Stochastic model specification search for Gaussian and partial non-Gaussian state space models. Journal of Econometrics 154(1), 85-100 
Geweke J (1992) Evaluating the Accuracy of Sampling Based Approaches to the Calculation of Posterior Moments. Bayesian Statistics 4, 169-188

Huber F (2016) Density forecasting using Bayesian global vector autoregressions with stochastic volatility. International Journal of Forecasting , forthcoming

Kamin SB (2010) Financial Globalization and Monetary Policy. International Finance Discussion Papers 1002, Board of Governors of the Federal Reserve System

Kastner G and Frühwirth-Schnatter S (2013) Ancillarity-sufficiency interweaving strategy (ASIS) for boosting MCMC estimation of stochastic volatility models. Computational Statistics \& Data Analysis 76, 408-423

Kim S (2001) International transmission of U.S. monetary policy shocks: Evidence from VAR's. Journal of Monetary Economics 48(2), 339-372

Lopes HF, McCulloch R and Tsay R (2013) Cholesky Stochastic Volatility Models for HighDimensional Time Series. Technical report, University of Chicago, mimeo.

Omori Y, Chib S, Shephard N and Nakajima J (2007) Stochastic volatility with leverage: Fast and efficient likelihood inference. Journal of Econometrics 140(2), 425-449

Orphanides A (2003) Historical monetary policy analysis and the Taylor rule. Journal of Monetary Economics 50(5), 983-1022

Pesaran MH, Schuermann T and Weiner SM (2004) Modeling Regional Interdependencies Using a Global Error-Correcting Macroeconometric Model. Journal of Business and Economic Statistics 22, 129-162

Pesaran MH and Shin Y (1998) Generalized impulse response analysis in linear multivariate models. Economics Letters 58(1), 17-29

Primiceri GE (2005) Time varying structural vector autoregressions and monetary policy. The Review of Economic Studies 72(3), 821-852

R Development Core Team (2011) R: A Language and Environment for Statistical Computing. $\mathrm{R}$ Foundation for Statistical Computing, Vienna, Austria. ISBN 3-900051-07-0

Rodgers DP (1985) Improvements in multiprocessor system design. In ACM SIGARCH Computer Architecture News, volume 13. IEEE Computer Society Press, 225-231

Rudebusch G and Svensson LE (1999) Policy rules for inflation targeting. In Monetary policy rules. University of Chicago Press, 203-262

Rue H (2001) Fast sampling of Gaussian Markov random fields. Journal of the Royal Statistical Society: Series B (Statistical Methodology) 63(2), 325-338

Sims CA and Zha T (2006) Were There Regime Switches in U.S. Monetary Policy? American Economic Review 96(1), 54-81

Taylor JB (1993) Discretion versus policy rules in practice. Carnegie-Rochester Conference Series on Public Policy 39(1), 195-214

Taylor JB (2002) The Monetary Transmission Mechanism and the Evaluation of Monetary Policy Rules. In Loayza N, Schmidt-Hebbel K, Editor) NLS and (Series KSH, eds., Monetary Policy: Rules and Transmission Mechanisms, volume 4 of Central Banking, Analysis, and Economic Policies Book Series, chapter 2. Central Bank of Chile, 021-046 
Table 1: Country coverage of GVAR model

\begin{tabular}{lllll}
\hline Europe & Other developed economies & Emerging Asia & Latin America & Mid-East and Africa \\
\hline Austria (AT) & Australia (AU) & China (CN) & Argentina (AR) & Turkey (TR) \\
Belgium (BE) & Canada (CA) & India (IN) & Brazil (BR) & Saudi Arabia (SA) \\
Germany (DE) & Japan (JP) & Indonesia (ID) & Chile (CL) & South Africa (ZA) \\
Spain (ES) & New Zealand (NZ) & Malaysia (MY) & Mexico (MX) & Peru (PE) \\
Finland (FI) & United States (US) & Korea (KR) & \\
France (FR) & & Philippines (PH) & \\
Greece (GR) & & Singapore (SG) & \\
Italy (IT) & Thailand (TH) & \\
Netherlands (NL) & & & \\
Portugal (PT) & & & \\
Denmark (DK) & & & \\
Great Britain (GB) & & & \\
Switzerland (CH) & & & \\
Norway (NO) & & & \\
Sweden (SE) & & & \\
\hline Notes: ISO-2 country codes in parentheses. Empirical results shown for countries in bold.
\end{tabular}


Table 2: Posterior distribution of US short-term interest rates responses to four regional shocks (GIRF).

\begin{tabular}{|c|c|c|c|c|c|c|c|c|c|c|}
\hline \multicolumn{11}{|c|}{ (a) Western Europe } \\
\hline \multirow[b]{3}{*}{ Shock to } & & \multirow{2}{*}{\multicolumn{3}{|c|}{$\begin{array}{l}\text { "Volcker" regime } \\
1979-1987\end{array}$}} & \multirow{2}{*}{\multicolumn{3}{|c|}{$\begin{array}{c}\text { "Greenspan" regime } \\
1987-2006\end{array}$}} & \multirow{2}{*}{\multicolumn{3}{|c|}{$\begin{array}{l}\text { "Bernanke" regime } \\
2006 \text { - } 2013\end{array}$}} \\
\hline & & & & & & & & & & \\
\hline & & Low $_{0.25}$ & Median & $\mathrm{High}_{0.75}$ & Low $_{0.25}$ & Median & High $_{0.75}$ & Low $_{0.25}$ & Median & $\operatorname{High}_{0.75}$ \\
\hline & $t=1$ & 6.7 & 41.9 & 95.5 & 22.7 & 64.8 & 132.5 & 32.6 & 94.7 & 171.9 \\
\hline Short-term interest rates & $t=8$ & -465.8 & -294.6 & -160.0 & -503.6 & -327.5 & -182.2 & -567.9 & -362.1 & -189.8 \\
\hline & $t=1$ & 12.9 & 43.9 & 79.6 & 33.3 & 73.7 & 120.6 & 5.6 & 35.9 & 65.1 \\
\hline Inflation & $t=8$ & -168.7 & -54.2 & 78.1 & -228.8 & -85.7 & 50.8 & -182.4 & -76.8 & 12.7 \\
\hline & $t=1$ & -165.8 & -122.0 & -79.0 & -134.1 & -97.1 & -64.3 & -126.6 & -91.1 & -58.2 \\
\hline Real GDP growth & $t=8$ & -214.5 & -107.2 & -38.4 & -156.0 & -79.0 & -20.7 & -138.8 & -62.6 & -15.8 \\
\hline & $t=1$ & -0.5 & 4.0 & 8.2 & -0.0 & 3.9 & 7.3 & -0.0 & 4.0 & 7.4 \\
\hline Exchange rate & $t=8$ & -9.8 & -2.2 & 5.8 & -8.0 & -1.6 & 4.4 & -6.8 & -0.4 & 5.7 \\
\hline \multicolumn{11}{|c|}{ (b) Asia } \\
\hline & & \multicolumn{3}{|c|}{$\begin{array}{l}\text { "Volcker" regime } \\
1979-1987\end{array}$} & \multicolumn{3}{|c|}{$\begin{array}{l}\text { "Greenspan" regime } \\
1987-2006\end{array}$} & \multicolumn{3}{|c|}{$\begin{array}{l}\text { "Bernanke" regime } \\
2006-2013\end{array}$} \\
\hline \multirow[t]{2}{*}{ Shock to } & & Low $_{0.25}$ & Median & High $_{0.75}$ & Low $_{0.25}$ & Median & $\operatorname{High}_{0.75}$ & Low $_{0.25}$ & Median & $\operatorname{High}_{0.75}$ \\
\hline & $t=1$ & -7.2 & -3.0 & 1.2 & -7.0 & -2.2 & 3.1 & -25.9 & -13.2 & -4.9 \\
\hline \multirow[t]{2}{*}{ Short-term interest rates } & $t=8$ & -43.2 & -25.9 & -13.2 & -59.3 & -36.1 & -20.2 & -80.0 & -46.3 & -26.3 \\
\hline & $t=1$ & 20.0 & 42.1 & 66.0 & 18.0 & 36.3 & 59.2 & 17.3 & 32.8 & 52.8 \\
\hline \multirow[t]{2}{*}{ Inflation } & $t=8$ & -106.2 & -54.8 & -3.4 & -107.8 & -59.0 & -9.4 & -85.6 & -43.8 & -6.1 \\
\hline & $t=1$ & -120.6 & -87.9 & -58.5 & -132.2 & -95.8 & -59.4 & -125.9 & -91.6 & -56.2 \\
\hline \multirow[t]{2}{*}{ Real GDP growth } & $t=8$ & -174.6 & -106.6 & -59.2 & -209.4 & -132.2 & -70.7 & -210.3 & -127.8 & -67.4 \\
\hline & $t=1$ & -10.5 & -5.0 & -0.1 & -10.1 & -5.0 & -0.5 & -12.9 & -6.5 & -1.8 \\
\hline Exchange rate & $t=8$ & -23.0 & -9.4 & 0.6 & -16.2 & -5.0 & 4.7 & -11.2 & -0.4 & 10.8 \\
\hline \multicolumn{11}{|c|}{ (c) Latin America } \\
\hline & & \multirow{2}{*}{\multicolumn{3}{|c|}{$\begin{array}{c}\text { "Volcker" regime } \\
1979-1987\end{array}$}} & \multirow{2}{*}{\multicolumn{3}{|c|}{$\begin{array}{c}\text { "Greenspan" regime } \\
1987-2006\end{array}$}} & \multirow{2}{*}{\multicolumn{3}{|c|}{$\begin{array}{l}\text { "Bernanke" regime } \\
2006-2013\end{array}$}} \\
\hline & & & & & & & & & & \\
\hline \multicolumn{2}{|l|}{ Shock to } & Low $_{0.25}$ & Median & $\mathrm{High}_{0.75}$ & $\operatorname{Low}_{0.25}$ & Median & $\mathrm{High}_{0.75}$ & Low $_{0.25}$ & Median & High $_{0.75}$ \\
\hline \multirow{3}{*}{ Short-term interest rates } & $t=1$ & -2.4 & -0.9 & 0.4 & -4.3 & -2.0 & 0.3 & -19.5 & -9.1 & -0.6 \\
\hline & $t=8$ & -0.8 & 3.3 & 8.6 & -6.6 & -0.6 & 5.7 & -34.2 & -11.0 & 5.3 \\
\hline & $t=1$ & -9.8 & 3.8 & 19.0 & -3.8 & 9.1 & 22.0 & -3.8 & 15.0 & 34.9 \\
\hline Inflation & $t=8$ & -40.9 & -1.9 & 25.5 & -34.0 & 2.6 & 28.9 & -45.4 & 0.9 & 40.4 \\
\hline \multirow{3}{*}{ Real GDP growth } & $t=1$ & -60.1 & -44.5 & -28.7 & -67.4 & -50.1 & -32.1 & -78.1 & -56.5 & -36.8 \\
\hline & $t=8$ & -91.0 & -56.5 & -30.9 & -99.6 & -63.3 & -33.6 & -111.3 & -67.7 & -34.6 \\
\hline & $t=1$ & -2.8 & 0.8 & 5.1 & -3.6 & 0.3 & 3.8 & -1.5 & 2.1 & 6.5 \\
\hline Exchange rate & $t=8$ & -14.7 & -6.4 & 2.1 & -19.2 & -9.2 & -1.9 & -22.3 & -11.2 & -4.7 \\
\hline
\end{tabular}


Figure 1: Real GDP growth responses to a +100 basis point (bp) US monetary policy shock

$$
\text { (a) } t=1
$$
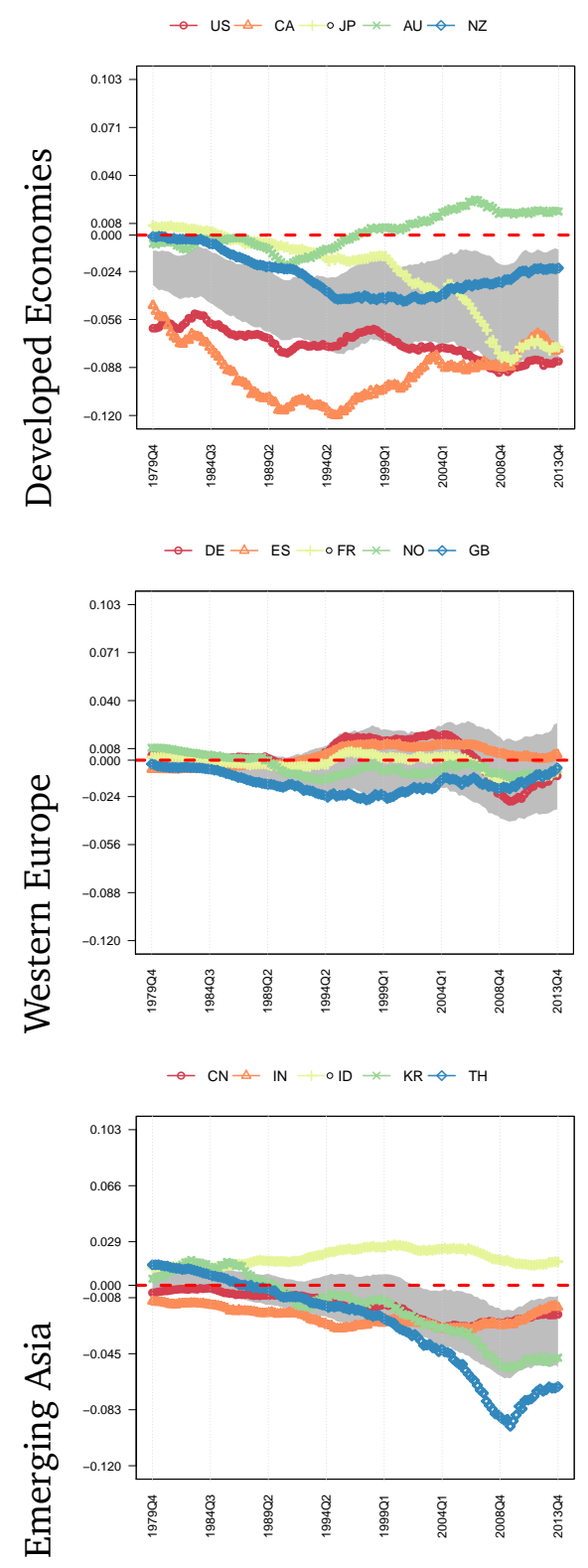

$$
\rightarrow \mathrm{BR} \backsim \mathrm{CL} \rightarrow \circ \mathrm{PE} \rightarrow \mathrm{MX} \rightarrow \mathrm{AR}
$$

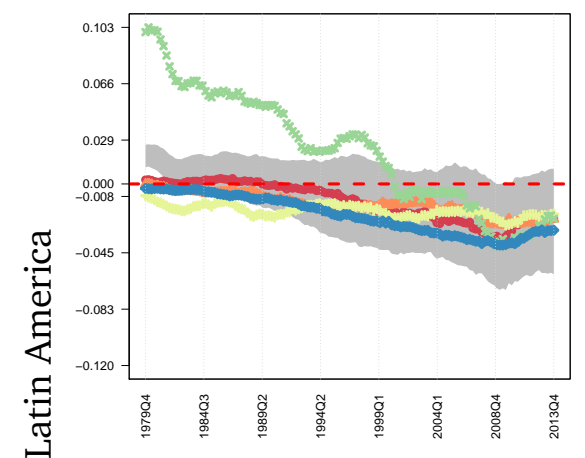

(b) $t=8$

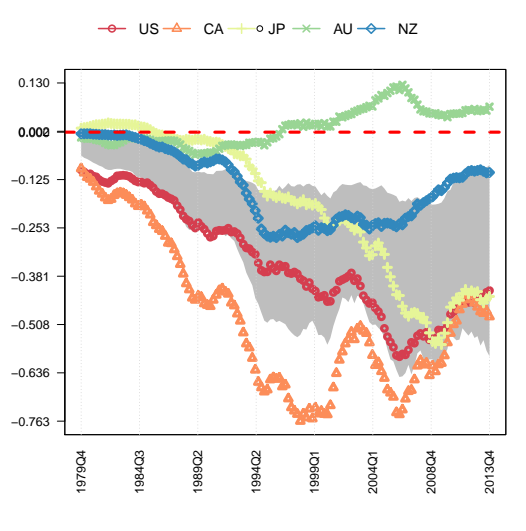

$\rightarrow \mathrm{DE} \triangle \mathrm{ES} \rightarrow O \mathrm{FR} \rightarrow \mathrm{NO} \rightarrow \mathrm{GB}$
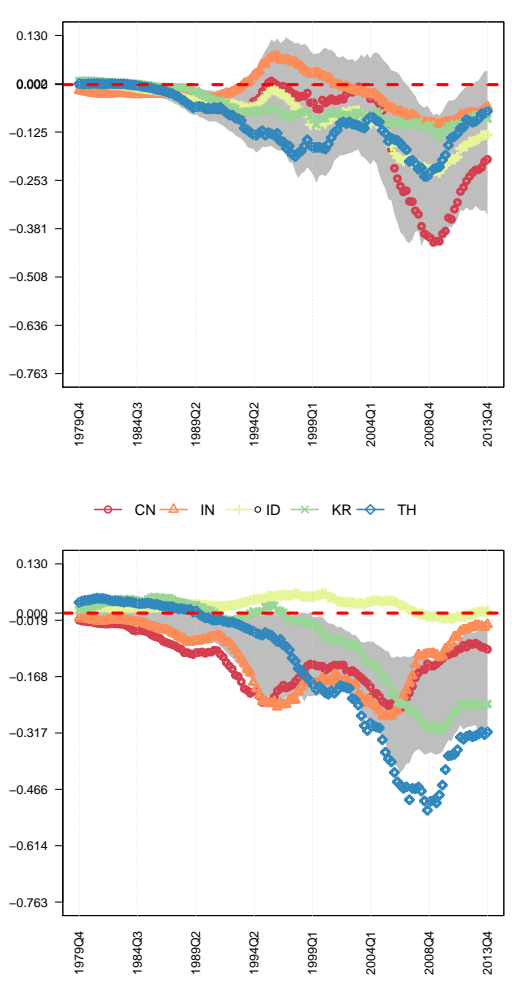

$\rightarrow \mathrm{BR} \triangle \mathrm{CL} \leftarrow \circ \mathrm{PE} * \mathrm{MX} \nrightarrow \mathrm{AR}$

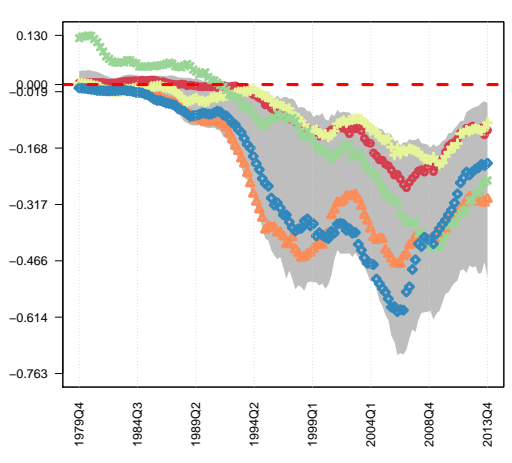

Notes: The plots show the posterior response for selected countries along with $25 \%$ and $75 \%$ credible sets of the crosscountry mean (gray shaded regions) after one and eight quarters. Responses are in cumulative terms and based on 1,500 posterior draws from a total chain of 30,000 draws. 
Figure 2: Inflation responses to a +100 basis point (bp) US monetary policy shock

(a) $t=1$
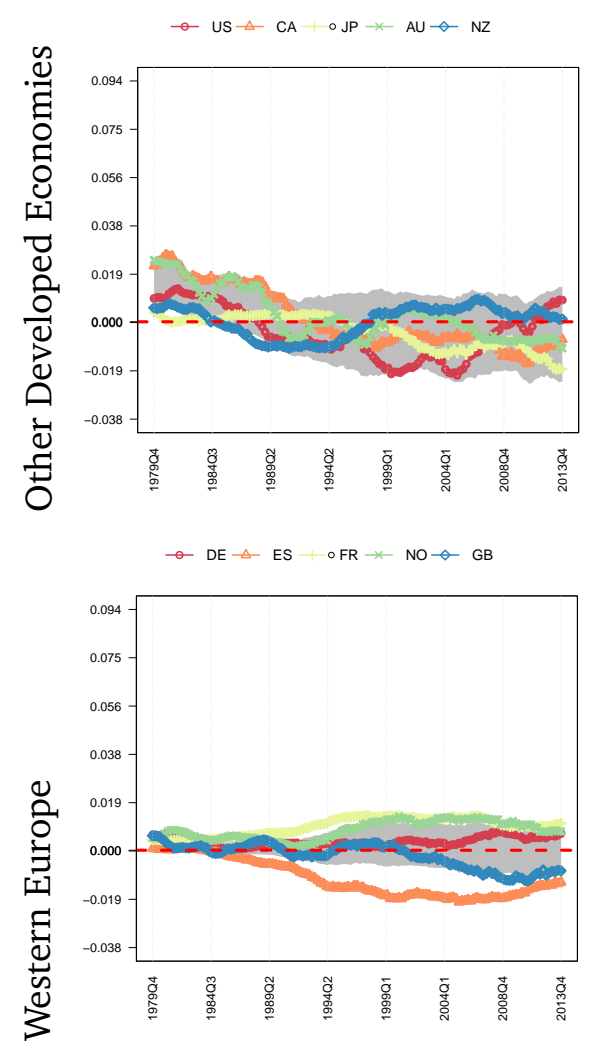

$\rightarrow C N \triangle I N \quad \circ I D \rightarrow K R \rightarrow T H$

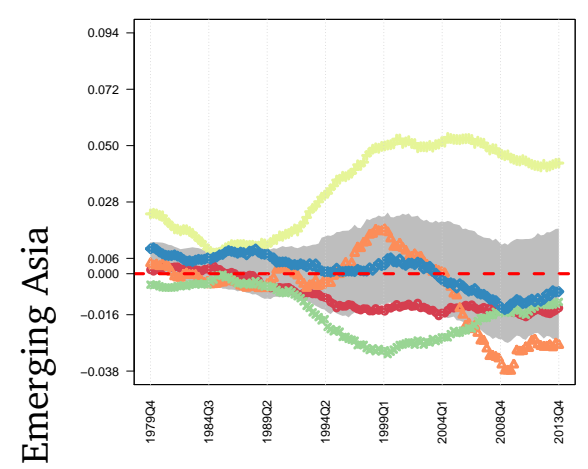

$$
\rightarrow \mathrm{BR} \leadsto \mathrm{CL} \rightarrow \mathrm{OPE} \rightarrow \mathrm{MX} \rightarrow \mathrm{AR}
$$

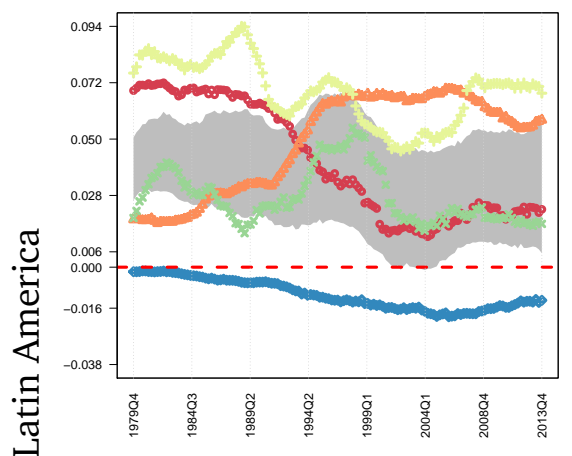

(b) $t=8$

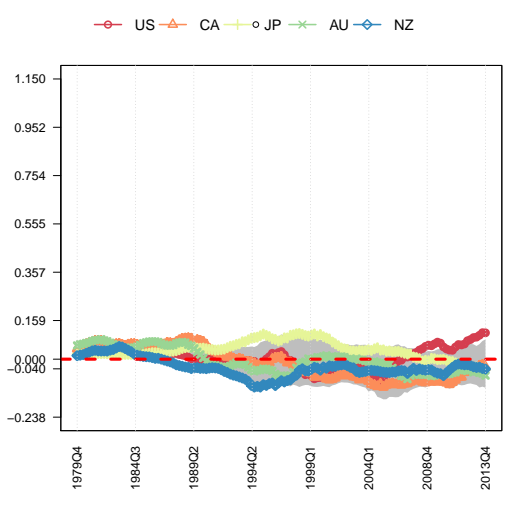

$\rightarrow \mathrm{DE} \triangle \mathrm{ES} \rightarrow O \mathrm{FR} \rightarrow \mathrm{NO} \rightarrow \mathrm{GB}$

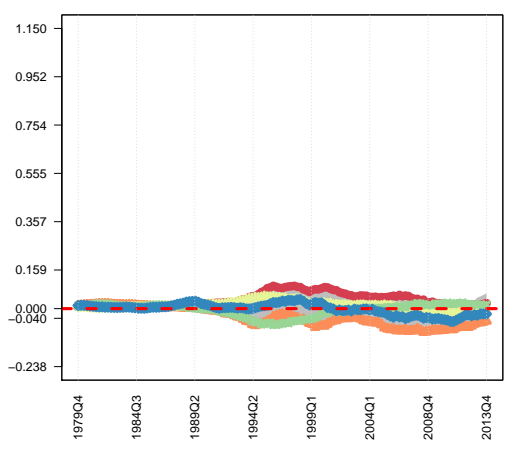

$\rightarrow \mathrm{CN} \triangle-\mathrm{IN} \rightarrow \circ \mathrm{ID} * \mathrm{KR} \bullet \mathrm{TH}$

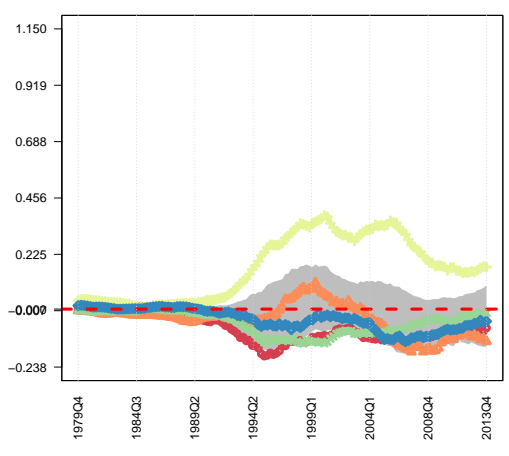

$\rightarrow \mathrm{BR} \leadsto \mathrm{CL} \rightarrow \mathrm{OPE} * \mathrm{MX} \rightarrow \mathrm{AR}$

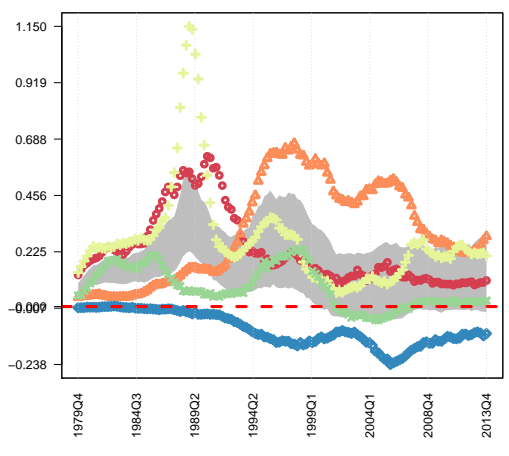

Notes: The plots show the posterior response for selected countries along with $25 \%$ and $75 \%$ credible sets of the crosscountry mean (gray shaded regions) after one and eight quarters. Responses are in cumulative terms and based on 1,500 posterior draws from a total chain of 30,000 draws. 
Figure 3: Short-term interest rate responses to a +100 basis point (bp) US monetary policy shock

(a) $t=1$

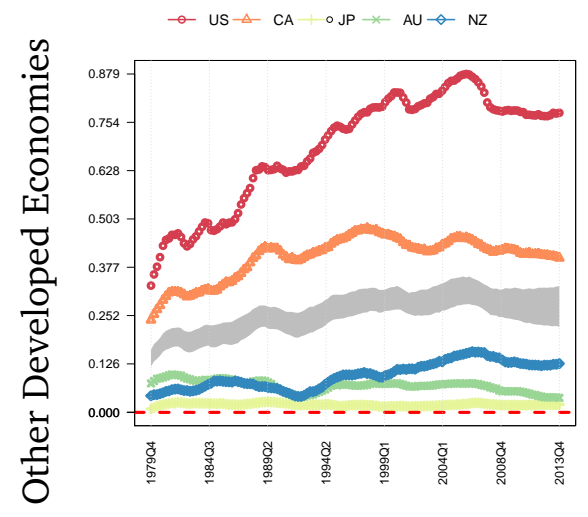

$\rightarrow \mathrm{DE} \triangle \mathrm{ES} \rightarrow \mathrm{FR} \rightarrow \mathrm{NO} \rightarrow \mathrm{GB}$

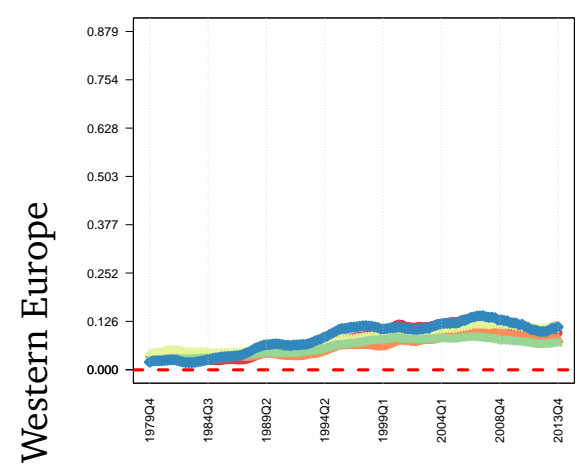

$\rightarrow C N-\triangle I N \quad \circ \mathrm{ID} \rightarrow \mathrm{KR} \rightarrow \mathrm{TH}$

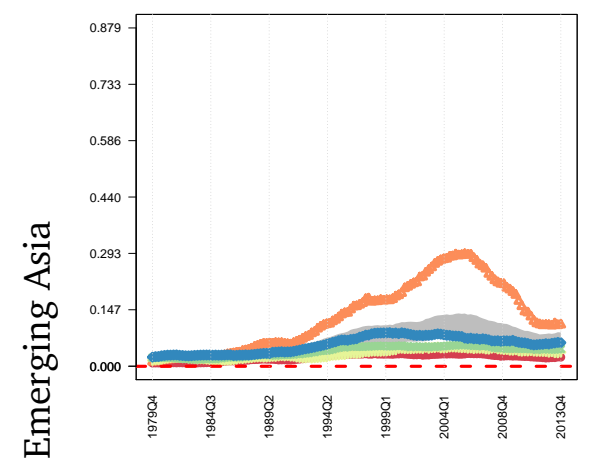

$\rightarrow \mathrm{BR} \leadsto \mathrm{CL} \rightarrow \circ \mathrm{PE} \rightarrow \mathrm{MX} \rightarrow \mathrm{AR}$

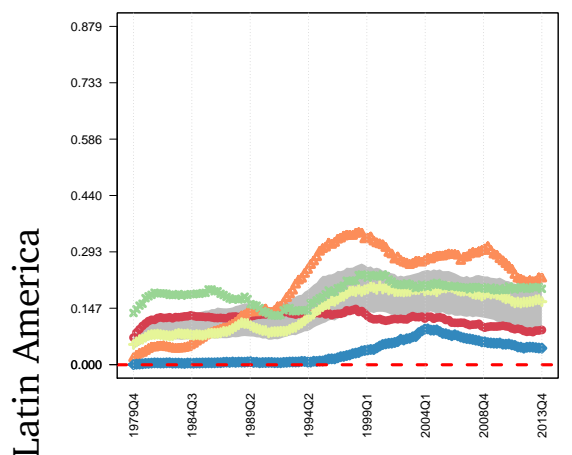

(b) $t=8$

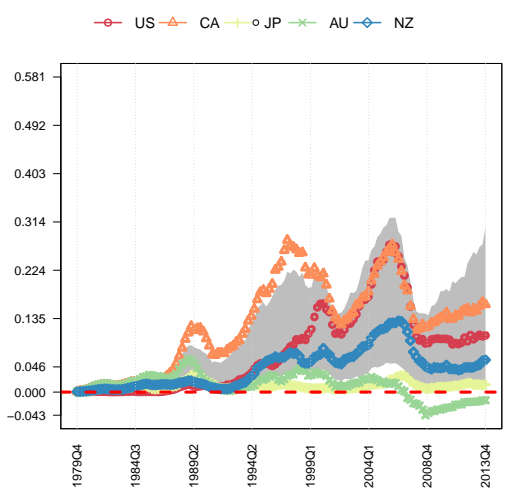

$\rightarrow \mathrm{DE} \triangle \mathrm{ES} \rightarrow \circ \mathrm{FR} * \mathrm{NO} \rightarrow \mathrm{GB}$

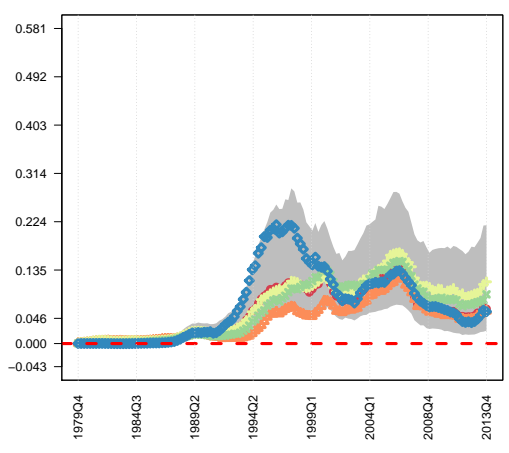

$-C N-\triangle N+O I D * K R \rightarrow T H$

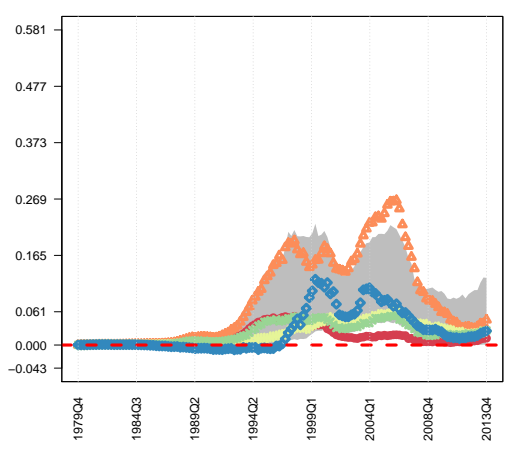

$\rightarrow \mathrm{BR} \leadsto \mathrm{CL} \nrightarrow \mathrm{OPE} \rightarrow \mathrm{MX} \rightarrow \mathrm{AR}$

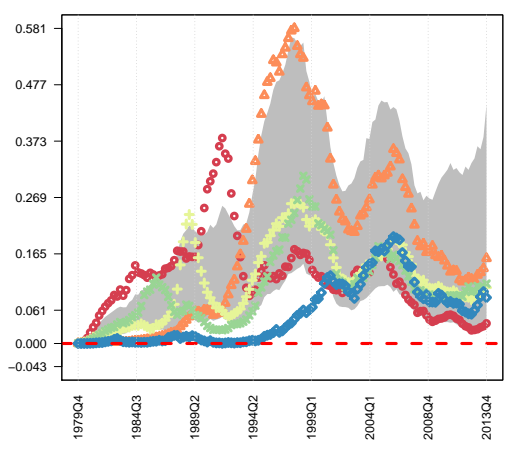

Notes: The plots show the posterior response for selected countries along with $25 \%$ and $75 \%$ credible sets of the crosscountry mean (gray shaded regions) after one and eight quarters. Responses are based on 1,500 posterior draws from a total chain of 30,000 draws. 
Figure 4: Real exchange rate responses to a +100 basis point (bp) US monetary policy shock

(a) $t=1$
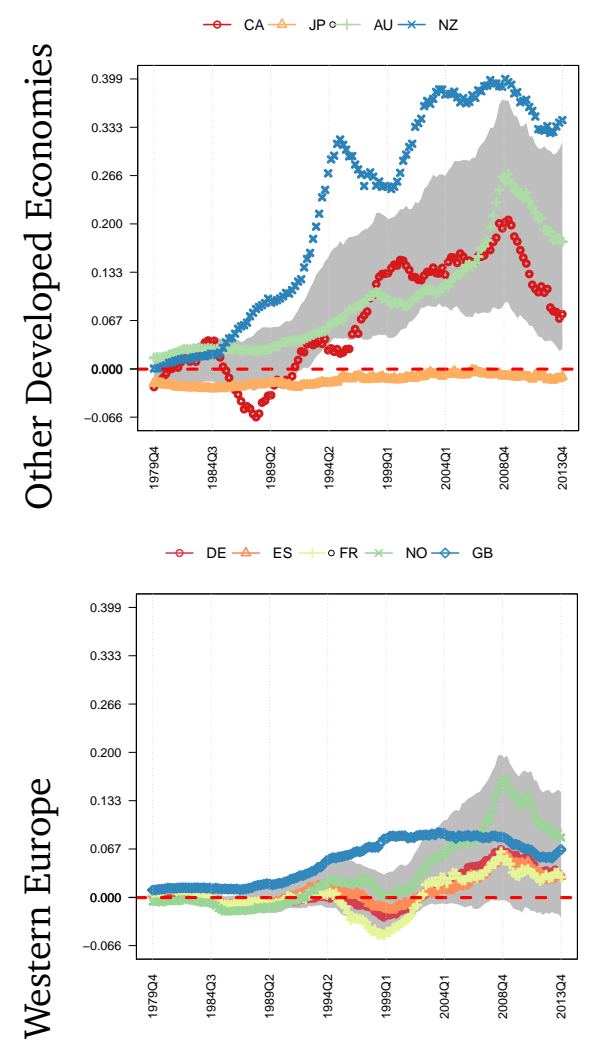

$\rightarrow C N \triangle I N \rightarrow I D \rightarrow K R \rightarrow T H$

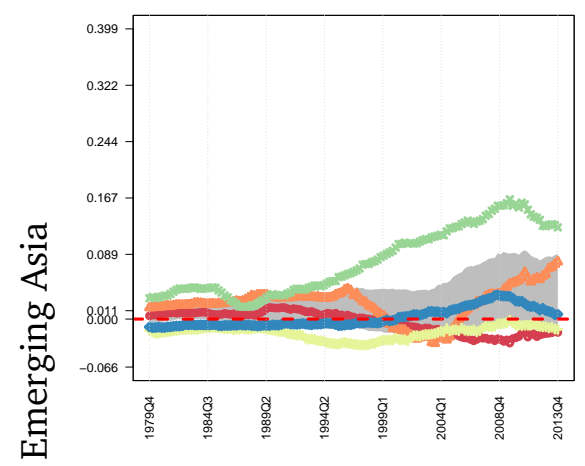

$\rightarrow \mathrm{BR} \leadsto \mathrm{CL} \rightarrow \circ \mathrm{PE} \rightarrow \mathrm{MX} \rightarrow \mathrm{AR}$

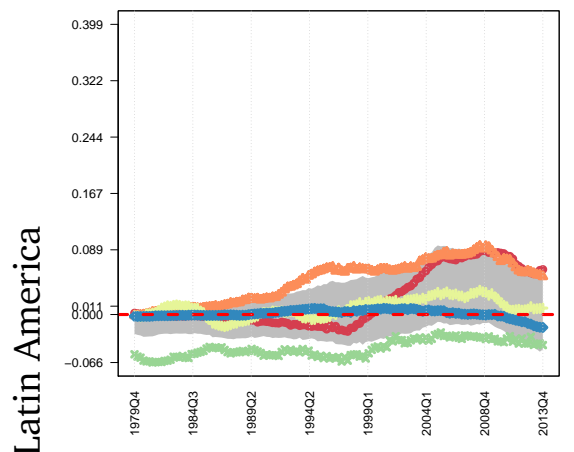

(b) $t=8$

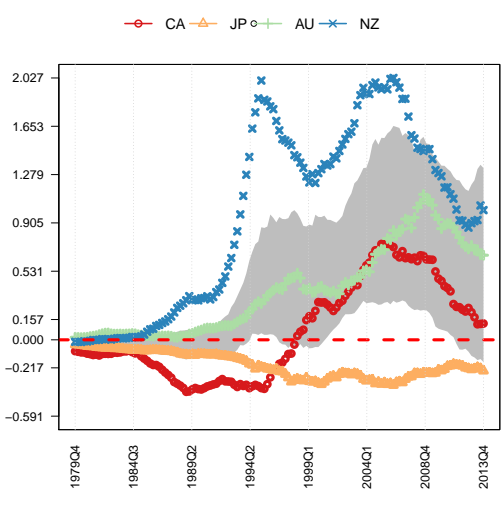

$\rightarrow \mathrm{DE} \rightarrow \mathrm{ES} \rightarrow O \mathrm{FR} \rightarrow \mathrm{NO} \rightarrow \mathrm{GB}$

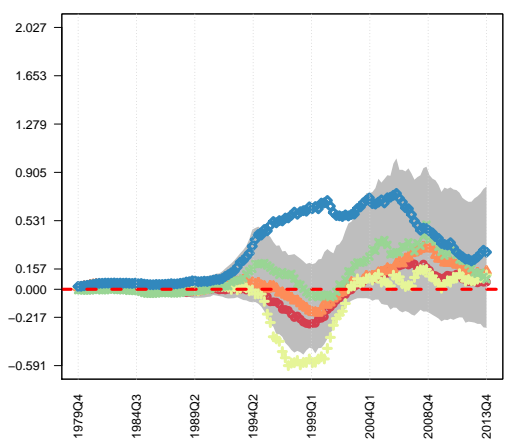

$\rightarrow C N \triangle I N \rightarrow O I D-K R \rightarrow T H$

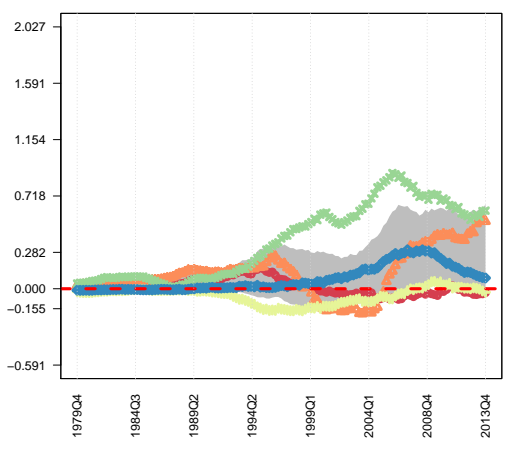

$\rightarrow \mathrm{BR} \triangle \mathrm{CL} \rightarrow \mathrm{OPE} \rightarrow \mathrm{MX} \rightarrow \mathrm{AR}$

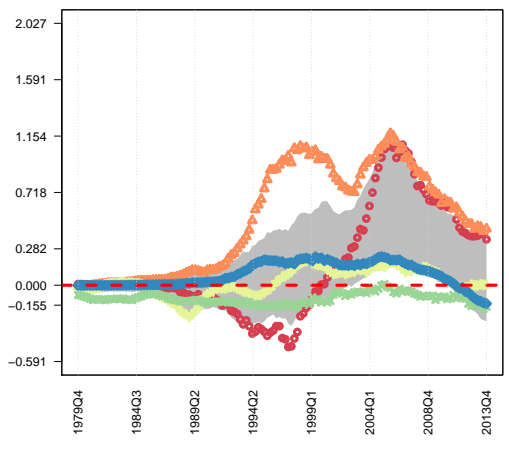

Notes: The plots show the posterior response for selected countries along with $25 \%$ and $75 \%$ credible sets of the crosscountry mean (gray shaded regions) after one and eight quarters. Responses are in cumulative terms and based on 1,500 posterior draws from a total chain of 30,000 draws. 
Figure 5: Stochastic volatility over time

(a) Real GDP growth
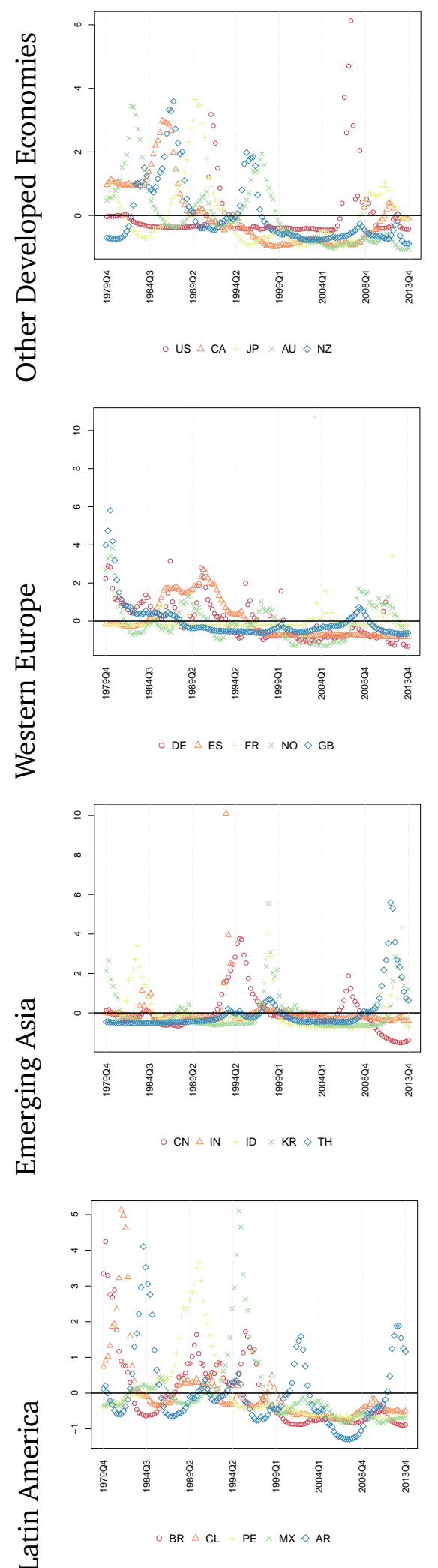

(b) Inflation

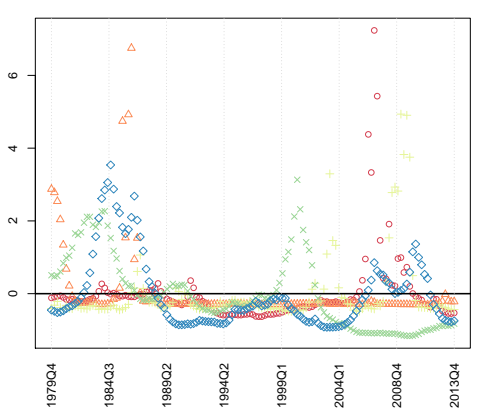

$\circ$ US $\triangle \mathrm{CA} \quad \mathrm{JP} \times \mathrm{AU} \diamond \mathrm{NZ}$
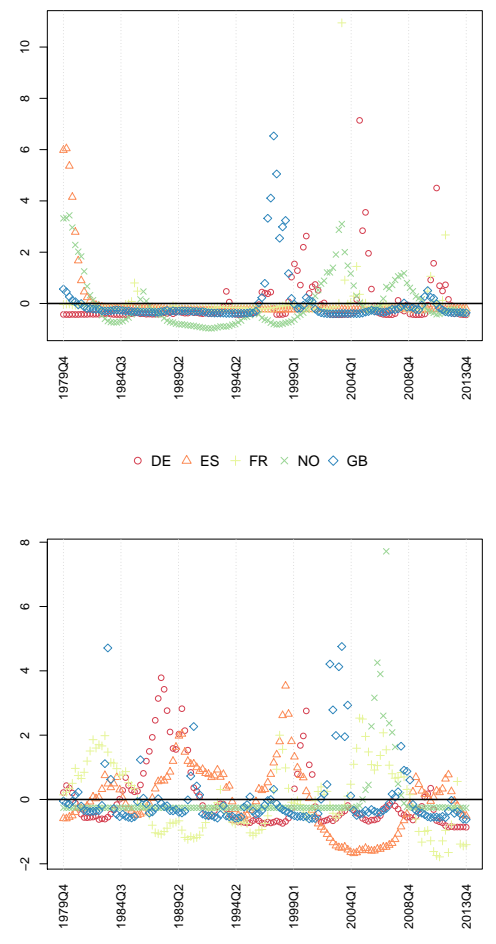

$\circ \mathrm{CN} \triangle \mathrm{IN} \quad \mathrm{ID} \times \mathrm{KR} \diamond \mathrm{TH}$

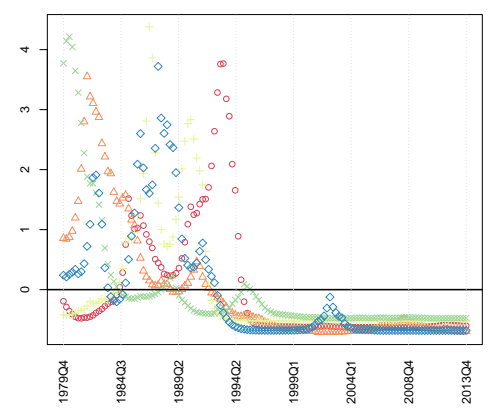

$\circ \mathrm{BR} \triangle \mathrm{CL} \quad \mathrm{PE} \times \mathrm{MX} \diamond \mathrm{AR}$

Notes: the plots depict the posterior mean of standardized volatility across regions over the estimation sample. Results based on 1,500 posterior draws from a total chain of 30,000 draws 
Figure 6: Stochastic volatility over time

(a) Short-term interest rates
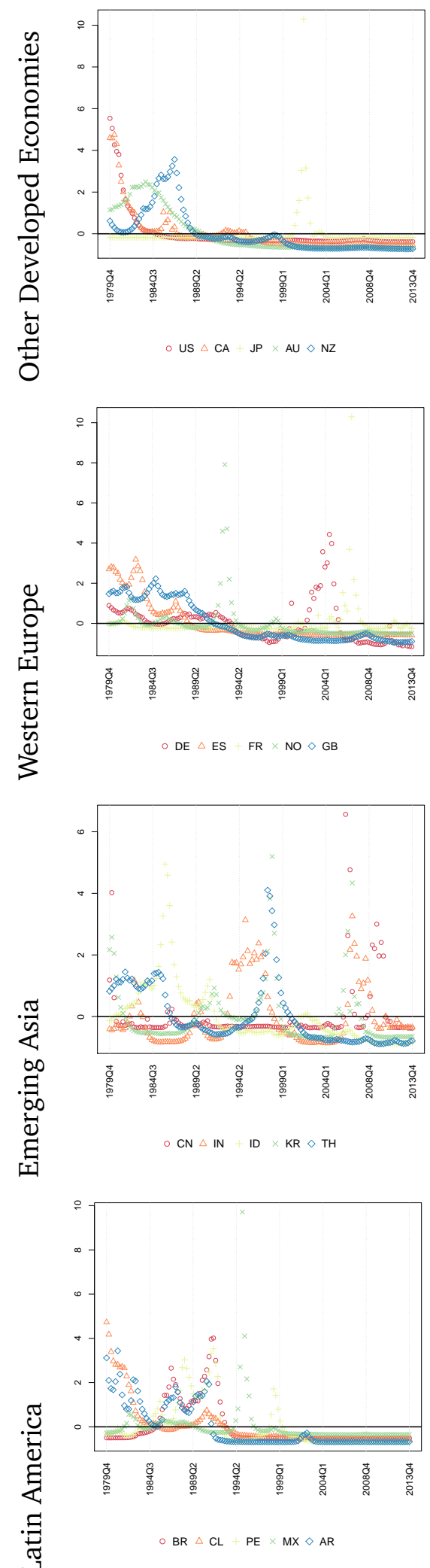

(b) Real exchange rate growth
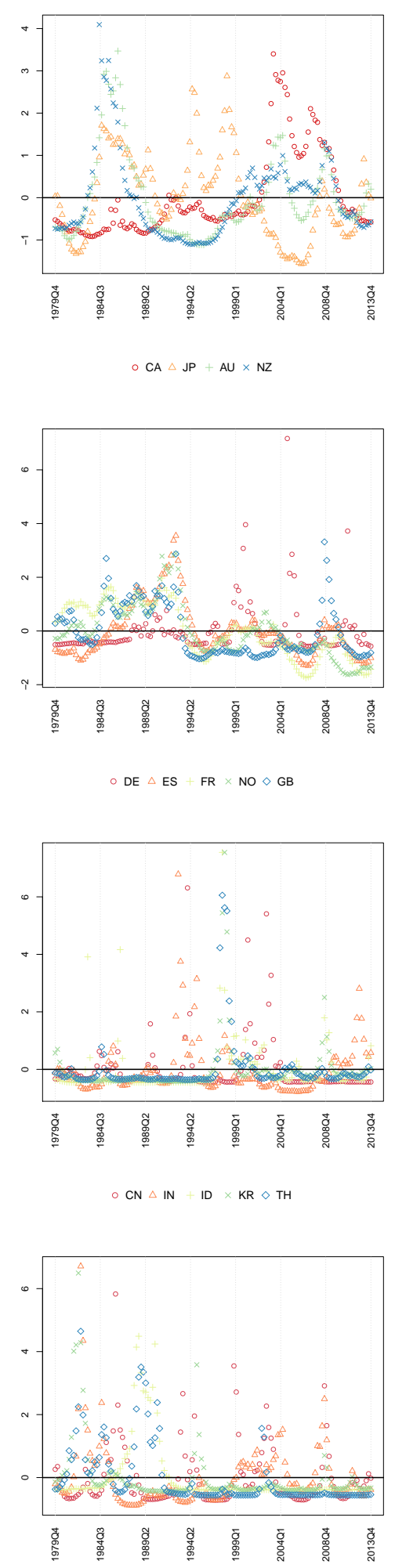

$\circ \mathrm{BR} \triangle \mathrm{CL}+\mathrm{PE} \times \mathrm{MX} \diamond \mathrm{AR}$

Notes: the plots depict the posterior mean of standardized volatility across regions over the estimation sample. Results based on 1,500 posterior draws from a total chain of 30,000 draws 
Figure 7: US short-term interest rate responses to regional shocks

(a) Short-term interest rate shock

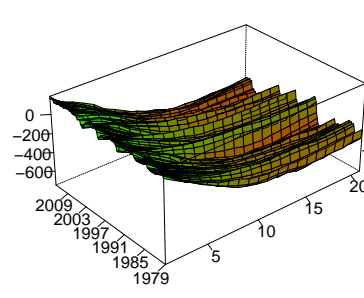

(e) Short-term interest rate shock

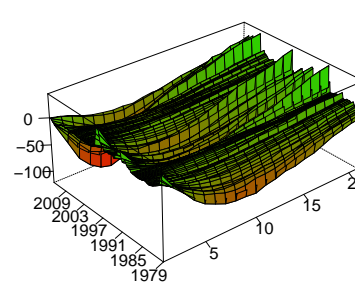

(i) Short-term interest rate shock

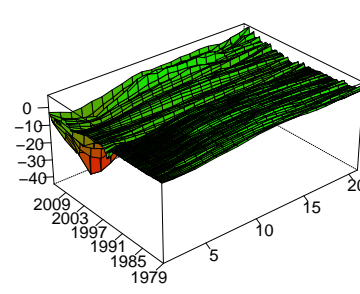

(b) Inflation shock

\section{Regional shock in Western Europe}

(c) Real GDP growth shock

(d) Exchange rate shock

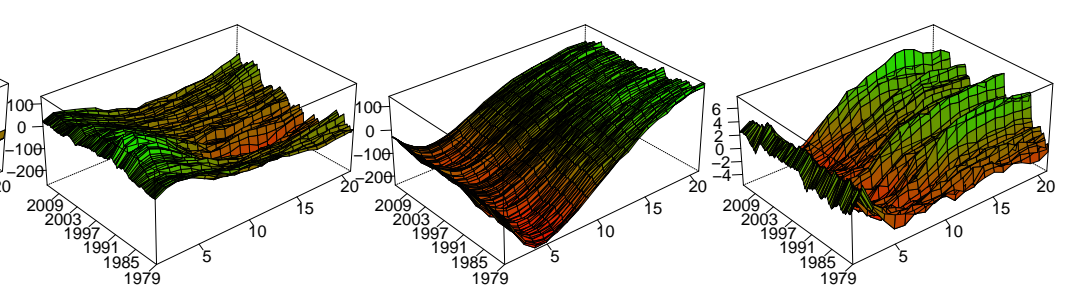

\section{Regional shock in Asia}

(f) Inflation shock

(g) Real GDP growth shock

(h) Exchange rate shock

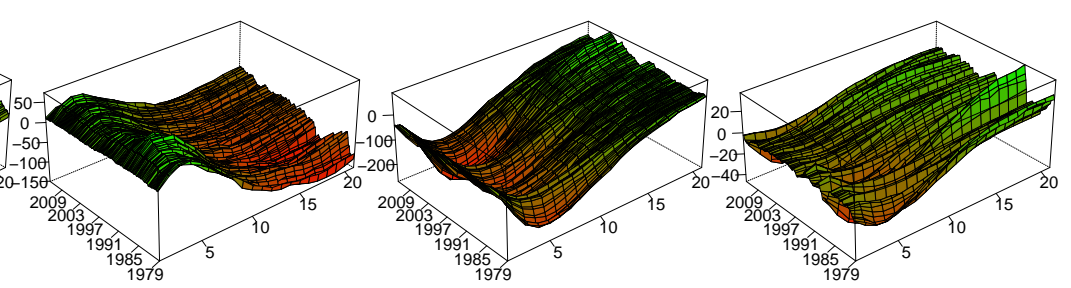

\section{Regional shock in Latin America}

(k) Real GDP growth (1) Exchange rate (j) Inflation shock shock shock

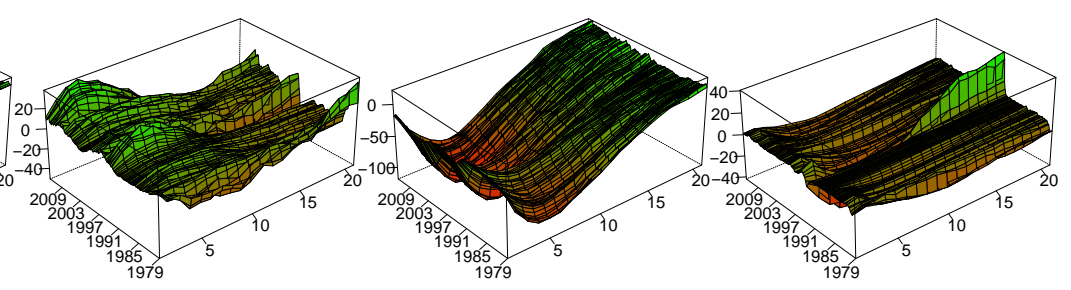

Notes: The plots depict the posterior mean of the generalized impulse response function of the short-term interest rates in basis points. The shocks are a regional rise in short-term interest rates, inflation, a reduction of regional real GDP growth and an appreciation of the US dollar against regional currency baskets. Responses are based on 1,500 posterior draws from a total chain of 30,000 draws. 


\section{Appendix A Additional technical information}

\section{A.1 Convergence properties of the MCMC algorithm}

As noted in Section 3, our MCMC algorithm is repeated 30,000 times, with the first 15,000 draws being discarded as burn-in. Inspection of a range of diagnostic checks indicate that the Markov chain converged to its stationary distribution. We consider the procedure proposed in Geweke (1992) to assess whether two non-overlapping parts of the Markov chain (in our case the first $10 \%$ and the final 50\%) come from the same statistical distribution. For the vast majority of parameters, the null hypothesis is confirmed at the $5 \%$ significance level.

In addition, inefficiency factors tend to be remarkably low, ranging from five to 20 for most parameters of the model. Values of inefficiency factors below 30 are typically considered to be satisfactory. These favorable convergence properties of our algorithm are not surprising given the fact that our model is a relatively simple TVP-SV-VAR with additional exogenous variables.

The trace plots of selected coefficients in some countries confirm the findings described above. We typically see well behaved distributions with low autocorrelation, again emphasizing the good properties of our sampler.

\section{A.2 Proof of Equation 2.19}

In what follows we prove the result for $v_{i j}^{2}$. The proof for $s_{i j}^{2}$ is very similar. Before proceeding to the proof, it is worth noting that the density of a generalized inverse Gaussian is proportional to $x^{\mathfrak{a}-1} \exp \left\{-\frac{1}{2}(\mathfrak{c} / x+\mathfrak{s} x)\right\}$.

Proof. Note that conditional on $a_{i j}^{T}=\left(a_{i j, 1} \ldots, a_{i j, T}\right)^{\prime}$, the conditional posterior of $v_{i j}^{2}$ is independent of the data. The conditional posterior is proportional to the likelihood times the Gamma prior,

$$
\begin{aligned}
p\left(v_{i j}^{2} \mid a_{i j}^{T}\right) & \propto\left(v_{i j}^{2}\right)^{-\frac{T}{2}} \times \exp \left\{-\frac{1}{2}\left(\frac{\sum_{t=1}^{T}\left(a_{i j, t}-a_{i j, t-1}\right)^{2}}{v_{i j}^{2}}\right)\right\} \times\left(v_{i j}^{2}\right)^{\frac{1}{2}-1} \times \exp \left(-\frac{1}{2 B_{v}} v_{i j}^{2}\right) \\
& \propto\left(v_{i j}^{2}\right)^{\left(\frac{1}{2}-\frac{T}{2}\right)-1} \exp \left\{-\frac{1}{2}\left(\frac{\sum_{t=1}^{T}\left(a_{i j, t}-a_{i j, t-1}\right)^{2}}{v_{i j}^{2}}+\frac{1}{2 B_{v}} v_{i j}^{2}\right)\right\},
\end{aligned}
$$

which is the kernel of a generalized inverse Gaussian distribution with $\mathfrak{a}=1 / 2-T / 2, \mathfrak{c}=$ $\sum_{t=1}^{T}\left(a_{i j, t}-a_{i j, t-1}\right)^{2}$ and $\mathfrak{s}=1 /\left(2 B_{v}\right)$.

\section{A.3 Sampling from the posterior of the log volatilities}

This appendix provides a brief overview of the MCMC algorithm put forward in Kastner and Frühwirth-Schnatter (2013), which is used as one of the required steps to sample from the posterior distribution of the parameters of our TVP-SV-GVAR model. We start by rewriting equation (2.5) as

$$
A_{i 0, t}^{-1} y_{i t}-\left(I_{k_{i}} \otimes x_{i t}^{\prime}\right) \operatorname{vec}\left(\Psi_{i t}\right)=\tilde{y}_{i t}=D_{i t}^{\frac{1}{2}} u_{i, t}
$$


Here $u_{i, t} \sim \mathcal{N}\left(0, I_{k_{i}}\right)$ and $D_{i t}=\left(D_{i t}^{\frac{1}{2}}\right)^{\prime} D_{i t}^{\frac{1}{2}}$. Kastner and Frühwirth-Schnatter (2013) consider $\lambda_{i j, t}$ in its centered parametrization given in equation (2.8) and in its non-centered form given by

$$
\ln \left(\tilde{\lambda}_{i j, t}\right)=\rho_{i j} \ln \left(\tilde{\lambda}_{i j, t-1}\right)+\nu_{i j, t} \text { for } j=1, \ldots, k_{i},
$$

where $\nu_{i j, t}$ is a standard normal error term.

Let us consider the $j$ th equation of equation (A.1). Squaring and taking logs yields

$$
\tilde{y}_{i j, t}^{2}=\ln \left(\lambda_{i j, t}\right)+\ln \left(u_{i j, t}^{2}\right) \text { for } j=1, \ldots, k_{i} .
$$

Since $\ln \left(u_{i, t}^{2}\right) \sim \log \chi^{2}(1)$, we follow Omori et al. (2007) and use a mixture of normal distributions to design the sampling procedure. This renders equation (A.3) conditionally Gaussian, i.e. $\ln \left(u_{i j, t}^{2} \mid r_{j, t}\right) \sim \mathcal{N}\left(m_{r_{i j, t}}, s_{r_{i j, t}}^{2}\right)$. The indicators controlling the mixture components prevailing at time $t$ are labeled as $r_{i j, t} \in\{1, \ldots, 10\} \cdot m_{r_{i, t}}$ and $s_{r_{i j, t}}^{2}$ denote the mean and variance of the corresponding mixture normal component, respectively.

Conditional on $r_{i j, t}$, we can rewrite equation (A.3) as a (conditionally) Gaussian linear state space model,

$$
\tilde{y}_{i j, t}^{2}=m_{r_{i j, t}}+\lambda_{i j, t}+\zeta_{i j, t}
$$

where $\zeta_{i j, t} \sim \mathcal{N}\left(0, s_{r_{i j, t}}^{2}\right)$

We simulate the history of log volatilities and the parameters of the state equation according to the following algorithm outlined in Kastner and Frühwirth-Schnatter (2013). The algorithm proceeds as follows:

1. Sample $\ln \left(\lambda_{i j,-1}\right) \mid r_{i j}, \mu_{i j}, \rho_{i j}, \varsigma_{i j}, \Psi_{i t}, A_{i 0, t}$ or $\ln \left(\tilde{\lambda}_{i j,-1}\right) \mid r_{i j}, \rho_{i j}, \zeta_{i j}, \Psi_{i t}, A_{i 0, t}$ all without a loop (AWOL). In the spirit of Rue (2001), it is possible to state $\ln \left(\lambda_{i j,-1}\right)=\left(\ln \left(\lambda_{i j, 2}\right), \ldots, \ln \left(\lambda_{i j, T}\right)\right)^{\prime}$ in terms of a multivariate normal distribution

$$
\ln \left(\lambda_{i j,-1}\right) \sim \mathcal{N}\left(\Omega_{\lambda_{i j}}^{-1} c_{i}, \Omega_{\lambda_{i, j}}^{-1}\right) .
$$

In a similar fashion, the distribution of the full state vector $\tilde{\lambda}_{i j,-1}=\left(\tilde{\lambda}_{i j, 2}, \ldots, \tilde{\lambda}_{i j, T}\right)$ is given by

$$
\ln \left(\tilde{\lambda}_{i j,-1}\right) \sim \mathcal{N}\left(\tilde{\Omega}_{\lambda_{i j}}^{-1} \tilde{c}_{i}, \tilde{\Omega}_{\lambda_{i j}}^{-1}\right) .
$$

In this expression, the posterior moments are given by

$$
\Omega_{\lambda_{i j}}=\left(\begin{array}{ccccc}
\frac{1}{s_{r_{i j, 2}}^{2}}+\frac{1}{\varsigma_{i j}^{2}} & \frac{-\rho_{i j}}{\varsigma_{i j}^{2}} & 0 & \cdots & 0 \\
-\frac{\rho_{i}}{\varsigma_{i j}^{2}} & \frac{1}{s_{r_{i, 3}}^{2}}+\frac{1+\rho_{i j}}{\varsigma_{i}^{2}} & -\frac{\rho_{i j}}{\varsigma_{i j}^{2}} & \ddots & \vdots \\
0 & -\frac{\rho_{i j}}{\varsigma_{i j}^{2}} & \ddots & \ddots & 0 \\
\vdots & \ddots & \ddots & \frac{1}{s_{r_{i j, T}}^{2}}+\frac{\rho_{i j}}{\varsigma_{i j}^{2}} & \frac{-\rho_{i j}}{\varsigma_{i j}^{2}} \\
0 & \cdots & 0 & \frac{1+\rho_{i j}}{\varsigma_{i j}^{2}} & \frac{1}{s_{r_{i j, T}}^{2}}+\frac{1}{\varsigma_{i j}^{2}}
\end{array}\right)
$$


and

$$
c_{i j}=\left(\begin{array}{c}
\frac{1}{s_{r_{i j, 2}}^{2}}\left(\tilde{y}_{i j, 2}^{2}-m_{r_{i j, 2}}\right)+\frac{\mu_{i j}\left(1-\rho_{i j}\right)}{\varsigma_{i j}^{2}} \\
\vdots \\
\frac{1}{s_{r_{i j, T}}^{2}}\left(\tilde{y}_{i j, T}^{2}-m_{r_{i j, T}}\right)+\frac{\mu_{i j}\left(1-\rho_{i j}\right)}{\varsigma_{i j}^{2}}
\end{array}\right) .
$$

The moments for the non-centered case are given by $\tilde{\Omega}_{i}=\varsigma_{i j}^{2} \Omega_{h_{i j}}$ and $\tilde{c}_{i j}=\varsigma_{i j}^{2} c_{i j}$. The initial states of $\ln \left(\lambda_{i j, 1}\right)$ and $\ln \left(\tilde{\lambda}_{i j, 1}\right)$ are obtained from the respective stationary distributions.

2. Sample the parameters of the state equations for both parameterizations. Due to the lack of conjugacy of the prior setup outlined in the main body, we combine Gibbs steps with Metropolis Hastings (MH) steps. We employ simple MH steps for the parameters of the state equations in (2.8) and (A.3). In the centered parametrization case, we sample $\mu_{i j}$ and $\rho_{i j}$ jointly using a Gibbs step and $\varsigma_{i j}^{2}$ is updated through a simple MH step. For the non-centered parametrization, $\rho_{i j}$ is sampled by means of a $\mathrm{MH}$ step and the remaining parameters are obtained by Gibbs sampling.

3. Sample the mixture indicators through inverse transform sampling. Finally, the indicators controlling the mixture distributions employed are obtained by inverse transform sampling in both cases. This step can be implemented by noting that $\tilde{y}_{i j, t}^{2}-\ln \left(\lambda_{i j, t}\right)=\tilde{u}_{i j, t}$ with $\tilde{u}_{i j, t} \sim \mathcal{N}\left(m_{r_{i j, t}}, s_{r_{i j, t}}^{2}\right)$. Posterior probabilities for each $r_{i j, t}$ are then given by

$$
p\left(r_{i j, t}=c \mid \bullet\right) \propto p\left(r_{i j, t}=c\right) \frac{1}{s_{i j, k}} \exp \left(-\frac{\left(\tilde{u}_{i j, t}-m_{i j, k}\right)}{2 s_{i j, t}^{2}}\right),
$$

where $p\left(r_{i j, t}=c\right)$ is the weight associated with the $c$ th component.

In the implementation of the present algorithm we simply draw the parameters under both parametrization and, depending on the relationship between the innovation variances of equation (A.1) and equation (2.8), we decide ex-post whether we should discard draws obtained from the centered parametrization or keep them. This constitutes the interweaving part of the algorithm. For further details we refer the reader to Kastner and FrühwirthSchnatter (2013). ${ }^{11}$

\section{A.4 Computational aspects of posterior inference in the TVP-SV-GVAR model}

Since our sampling scheme treats countries and equations as isolated estimation problems, parallel computing can be exploited to carry out posterior inference in the TVP-GVAR model. Such a modeling strategy proves to be an efficient means of estimating high-dimensional GVARs with drifting parameters, while imposing parametric restrictions only on the international linkages that take place through the weakly exogenous variables.

\footnotetext{
${ }^{11}$ The steps described here are implemented using the stochvol package in $\mathrm{R}$, a language and environment for statistical computing (R Development Core Team, 2011).
} 
The combination of the Cholesky structure in equation (2.2) and the presence of the weakly exogenous variables permit equation-by-equation and country-by-country estimation. This constitutes an estimation strategy that relies heavily on parallel computation to obtain parameter estimates for equation (2.11). The first strategy views the GVAR model as a system of $k$ unrelated regression models, which can be spread across $\varrho$ processors. In this case, the maximum speedup gained by parallelization is given by

$$
\text { Maximum Speedup }=\frac{1}{\frac{f}{\varrho}+(1-f)} .
$$

Here, $f$ denotes the fraction of the problem which can be parallelized. Equation (A.10) is known as Amdahl's law (Rodgers, 1985) in computer science. If $f$ equals unity the task at hand is called embarrassingly parallel, making it perfectly suitable for parallel computing. In the GVAR setting, $f$ is close to unity after taking into account the costs of distributing the information across the different processing units. In addition, it is worth emphasizing that since we impose a triangular structure on the model and the number of endogenous variables per country model differs (note that in general, $k_{i} \neq k_{j} \forall j, i$ ), the number of parameters differs from equation to equation. The maximum computation time is bounded by the time required to estimate the equation with the maximum number of parameters. If the number of CPU cores $\varrho$ equals $k$, computation time almost boils down to that required for estimating the equation with the maximum number of parameters. 


\section{Appendix B Additional results}

Table B.1: Posterior distribution of US short-term interest rates responses to four regional shocks, recursive identification

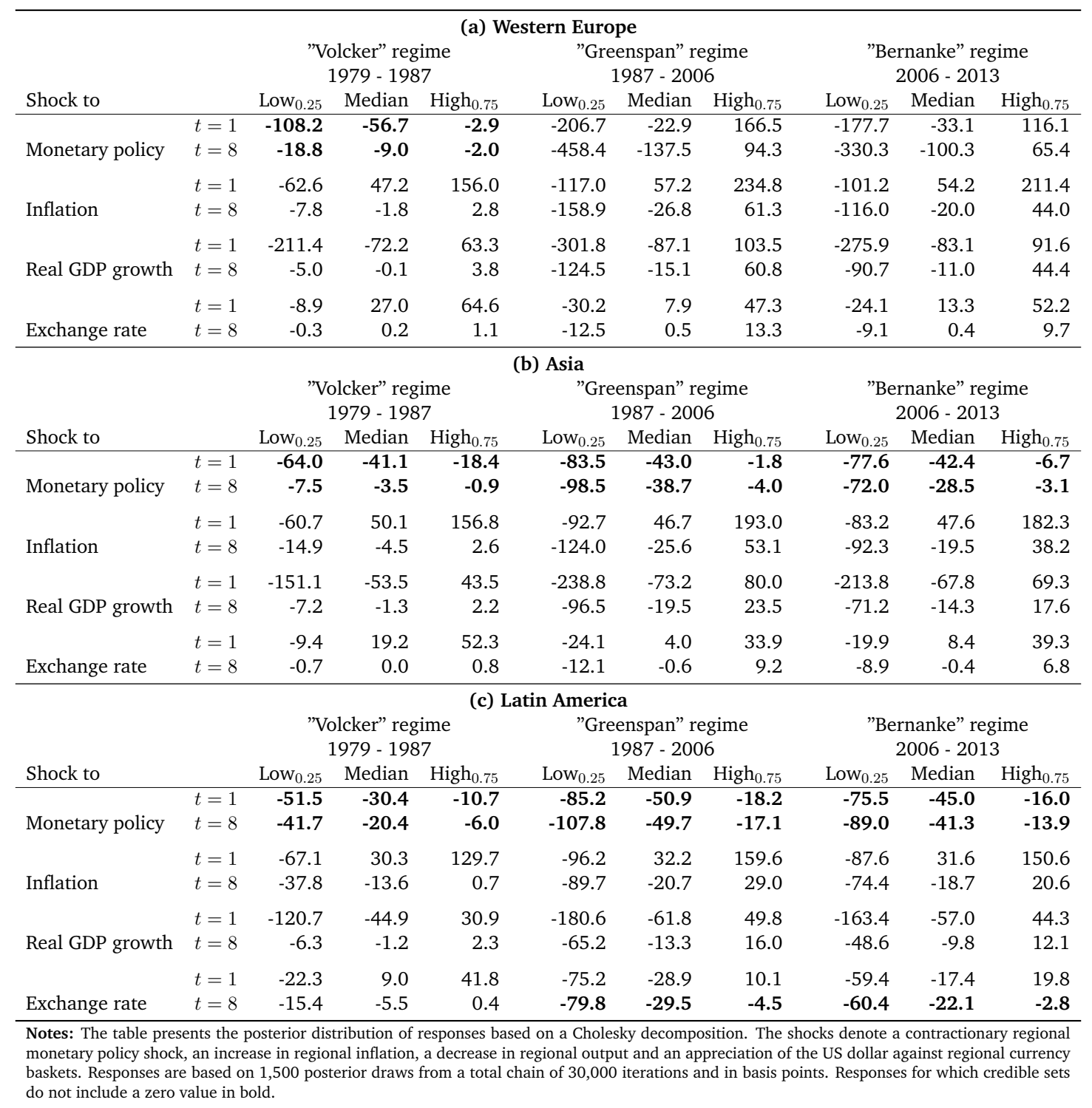




\section{Index of Working Papers:}

\begin{tabular}{|c|c|c|c|}
\hline May 29, 2009 & Helmut Elsinger & 156 & $\begin{array}{l}\text { Financial Networks, Cross Holdings, and } \\
\text { Limited Liability }\end{array}$ \\
\hline July 20, 2009 & Simona Delle Chiaie & 157 & $\begin{array}{l}\text { The sensitivity of DSGE models' results to } \\
\text { data detrending }\end{array}$ \\
\hline $\begin{array}{l}\text { November 10, } \\
2009\end{array}$ & $\begin{array}{l}\text { Markus Knell } \\
\text { Helmut Stix }\end{array}$ & 158 & $\begin{array}{l}\text { Trust in Banks? } \\
\text { Evidence from normal times } \\
\text { and from times of crises }\end{array}$ \\
\hline $\begin{array}{l}\text { November 27, } \\
2009\end{array}$ & $\begin{array}{l}\text { Thomas Scheiber } \\
\text { Helmut Stix }\end{array}$ & 159 & $\begin{array}{l}\text { Euroization in Central, Eastern and South- } \\
\text { eastern Europe - New Evidence On Its } \\
\text { Extent and Some Evidence On Its Causes }\end{array}$ \\
\hline $\begin{array}{l}\text { January } 11 \\
2010\end{array}$ & $\begin{array}{l}\text { Jesús Crespo } \\
\text { Cuaresma } \\
\text { Martin Feldircher }\end{array}$ & 160 & $\begin{array}{l}\text { Spatial Filtering, Model Uncertainty and the } \\
\text { Speed of Income Convergence in Europe }\end{array}$ \\
\hline $\begin{array}{l}\text { March 29, } \\
2010\end{array}$ & Markus Knell & 161 & $\begin{array}{l}\text { Nominal and Real Wage Rigidities. } \\
\text { In Theory and in Europe }\end{array}$ \\
\hline May 31, 2010 & $\begin{array}{l}\text { Zeno Enders } \\
\text { Philip Jung } \\
\text { Gernot J. Müller }\end{array}$ & 162 & Has the Euro changed the Business Cycle? \\
\hline $\begin{array}{l}\text { August 25, } \\
2010\end{array}$ & $\begin{array}{l}\text { Marianna ervená } \\
\text { Martin Schneider }\end{array}$ & 163 & $\begin{array}{l}\text { Short-term forecasting GDP with a DSGE } \\
\text { model augmented by monthly indicators }\end{array}$ \\
\hline $\begin{array}{l}\text { September 8, } \\
2010\end{array}$ & $\begin{array}{l}\text { Sylvia Kaufmann } \\
\text { Johann Scharler }\end{array}$ & 164 & $\begin{array}{l}\text { Bank-Lending Standards, the Cost Channel } \\
\text { and Inflation Dynamics }\end{array}$ \\
\hline $\begin{array}{l}\text { September 15, } \\
2010\end{array}$ & Helmut Elsinger & 165 & $\begin{array}{l}\text { Independence Tests based on Symbolic } \\
\text { Dynamics }\end{array}$ \\
\hline $\begin{array}{l}\text { December 14, } \\
2010\end{array}$ & Claudia Kwapil & 166 & $\begin{array}{l}\text { Firms' Reactions to the Crisis and their } \\
\text { Consequences for the Labour Market. } \\
\text { Results of a Company Survey conducted in } \\
\text { Austria }\end{array}$ \\
\hline May 10,2011 & Helmut Stix & 167 & $\begin{array}{l}\text { Does the Broad Public Want to Consolidate } \\
\text { Public Debt? - The Role of Fairness and of } \\
\text { Policy Credibility }\end{array}$ \\
\hline
\end{tabular}




\begin{tabular}{|c|c|c|c|}
\hline May 11,2011 & $\begin{array}{l}\text { Burkhard Raunig, } \\
\text { Johann Scharler }\end{array}$ & 168 & $\begin{array}{l}\text { Stock Market Volatility, Consumption and } \\
\text { Investment; An Evaluation of the Uncertainty } \\
\text { Hypothesis Using Post-War U.S. Data }\end{array}$ \\
\hline May 23, 2011 & Steffen Osterloh & 169 & $\begin{array}{l}\text { Can Regional Transfers Buy Public } \\
\text { Support? Evidence from EU Structural } \\
\text { Policy }\end{array}$ \\
\hline May 23, 2011 & $\begin{array}{l}\text { Friederike Niepmann } \\
\text { Tim Schmidt-Eisenlohr }\end{array}$ & 170 & $\begin{array}{l}\text { Bank Bailouts, International Linkages and } \\
\text { Cooperation }\end{array}$ \\
\hline $\begin{array}{l}\text { September 1, } \\
2011\end{array}$ & $\begin{array}{l}\text { Jarko Fidrmuc, } \\
\text { Mariya Hake, } \\
\text { Helmut Stix }\end{array}$ & 171 & $\begin{array}{l}\text { Households' Foreign Currency Borrowing in } \\
\text { Central and Eastern Europe }\end{array}$ \\
\hline $\begin{array}{l}\text { September 9, } \\
2011\end{array}$ & $\begin{array}{l}\text { Jürgen Eichberger, } \\
\text { Klaus Rheinberger, } \\
\text { Martin Summer }\end{array}$ & 172 & Credit Risk in General Equilibrium \\
\hline $\begin{array}{l}\text { October 6, } \\
2011\end{array}$ & Peter Lindner & 173 & $\begin{array}{l}\text { Decomposition of Wealth and Income using } \\
\text { Micro Data from Austria }\end{array}$ \\
\hline $\begin{array}{l}\text { October 18, } \\
2011\end{array}$ & Stefan Kerbl & 174 & $\begin{array}{l}\text { Regulatory Medicine Against Financial } \\
\text { Market Instability: } \\
\text { What Helps And What Hurts? }\end{array}$ \\
\hline $\begin{array}{l}\text { December 31, } \\
2011\end{array}$ & $\begin{array}{l}\text { Konstantins Benkovskis } \\
\text { Julia Wörz }\end{array}$ & 175 & How Does Quality Impact on Import Prices? \\
\hline $\begin{array}{l}\text { January 17, } \\
2012\end{array}$ & Nicolás Albacete & 176 & $\begin{array}{l}\text { Multiple Imputation in the Austrian } \\
\text { Household Survey on Housing Wealth }\end{array}$ \\
\hline $\begin{array}{l}\text { January 27, } \\
2012\end{array}$ & $\begin{array}{l}\text { Gerhard Fenz, } \\
\text { Lukas Reiss, } \\
\text { Martin Schneider }\end{array}$ & 177 & $\begin{array}{l}\text { A structural interpretation of the impact of } \\
\text { the great recession on the Austrian } \\
\text { economy using an estimated DSGE model }\end{array}$ \\
\hline $\begin{array}{l}\text { July } 27 \\
2012\end{array}$ & Helmut Stix & 178 & $\begin{array}{l}\text { Why Do People Save in Cash? Distrust, } \\
\text { Memories of Banking Crises, Weak } \\
\text { Institutions and Dollarization }\end{array}$ \\
\hline $\begin{array}{l}\text { August 20, } \\
2012\end{array}$ & Markus Knell & 179 & $\begin{array}{l}\text { Increasing Life Expectancy and Pay-As- } \\
\text { You-Go Pension Systems }\end{array}$ \\
\hline $\begin{array}{l}\text { September 25, } \\
2012\end{array}$ & $\begin{array}{l}\text { Fabio Rumler, } \\
\text { Walter Waschiczek }\end{array}$ & 180 & $\begin{array}{l}\text { Have Changes in the Financial Structure } \\
\text { Affected Bank Protability? Evidence for } \\
\text { Austria }\end{array}$ \\
\hline
\end{tabular}




\begin{tabular}{|c|c|c|c|}
\hline $\begin{array}{l}\text { November 9, } \\
2012\end{array}$ & $\begin{array}{l}\text { Elisabeth Beckmann, } \\
\text { Jarko Fidrmuc, } \\
\text { Helmut Stix }\end{array}$ & 181 & $\begin{array}{l}\text { Foreign Currency Loans and Loan Arrears } \\
\text { of Households in Central and Eastern } \\
\text { Europe }\end{array}$ \\
\hline $\begin{array}{l}\text { June 10, } \\
2013\end{array}$ & Luca Fornaro & 182 & International Debt Deleveraging \\
\hline $\begin{array}{l}\text { June 10, } \\
2013\end{array}$ & $\begin{array}{l}\text { Jenny Simon, } \\
\text { Justin Valasek }\end{array}$ & 183 & $\begin{array}{l}\text { Efficient Fiscal Spending by Supranational } \\
\text { Unions }\end{array}$ \\
\hline $\begin{array}{l}\text { July } 24 \\
2013\end{array}$ & $\begin{array}{l}\text { Thomas Breuer, Hans- } \\
\text { Joachim Vollbrecht, } \\
\text { Martin Summer }\end{array}$ & 184 & $\begin{array}{l}\text { Endogenous Leverage and Asset Pricing in } \\
\text { Double Auctions }\end{array}$ \\
\hline $\begin{array}{l}\text { September 23, } \\
2013\end{array}$ & Martin Feldkircher & 185 & A Global Macro Model for Emerging Europe \\
\hline $\begin{array}{l}\text { September 25, } \\
2013\end{array}$ & $\begin{array}{l}\text { Martin Gächter, } \\
\text { Aleksandra Riedl }\end{array}$ & 186 & $\begin{array}{l}\text { One Money, One Cycle? The EMU } \\
\text { Experience }\end{array}$ \\
\hline $\begin{array}{l}\text { December 9, } \\
2013\end{array}$ & $\begin{array}{l}\text { Stefan Niemann, } \\
\text { Paul Pichler }\end{array}$ & 187 & Collateral, Liquidity and Debt Sustainability \\
\hline $\begin{array}{l}\text { March 6, } \\
2014\end{array}$ & $\begin{array}{l}\text { Elisabeth Beckmann, } \\
\text { Helmut Stix }\end{array}$ & 188 & $\begin{array}{l}\text { Foreign currency borrowing and knowledge } \\
\text { about exchange rate risk }\end{array}$ \\
\hline $\begin{array}{l}\text { March 10, } \\
2014\end{array}$ & $\begin{array}{l}\text { Jesús Crespo } \\
\text { Cuaresma, } \\
\text { Martin Feldkircher, } \\
\text { Florian Huber }\end{array}$ & 189 & $\begin{array}{l}\text { Forecasting with Bayesian Global Vector } \\
\text { Autoregressive Models: } \\
\text { A Comparison of Priors }\end{array}$ \\
\hline $\begin{array}{l}\text { May 12, } \\
2014\end{array}$ & Claudia Steinwender & 190 & $\begin{array}{l}\text { Information Frictions and the Law of One } \\
\text { Price: "When the States and the Kingdom } \\
\text { became United" }\end{array}$ \\
\hline $\begin{array}{l}\text { May 12, } \\
2014\end{array}$ & Saleem A. Bahaj & 191 & $\begin{array}{l}\text { Systemic Sovereign Risk: Macroeconomic } \\
\text { Implications in the Euro Area }\end{array}$ \\
\hline $\begin{array}{l}\text { May 16, } \\
2014\end{array}$ & $\begin{array}{l}\text { John Bagnall, } \\
\text { David Bounie, } \\
\text { Kim P. Huynh, } \\
\text { Anneke Kosse, } \\
\text { Tobias Schmidt, } \\
\text { Scott Schuh and } \\
\text { Helmut Stix }\end{array}$ & 192 & $\begin{array}{l}\text { Consumer Cash Usage: A Cross-Country } \\
\text { Comparison with Payment Diary Survey } \\
\text { Data }\end{array}$ \\
\hline $\begin{array}{l}\text { May 19, } \\
2014\end{array}$ & $\begin{array}{l}\text { Konstantins Benkovskis } \\
\text { Julia Wörz }\end{array}$ & 193 & $\begin{array}{l}\text { "Made in China" - How Does it Affect } \\
\text { Measures of Competitiveness? }\end{array}$ \\
\hline
\end{tabular}




\begin{tabular}{|c|c|c|c|}
\hline $\begin{array}{l}\text { June 25, } \\
2014\end{array}$ & $\begin{array}{l}\text { Burkhard Raunig, } \\
\text { Johann Scharler and } \\
\text { Friedrich Sindermann }\end{array}$ & 194 & Do Banks Lend Less in Uncertain Times? \\
\hline $\begin{array}{l}\text { July 28, } \\
2014\end{array}$ & $\begin{array}{l}\text { Martin Feldkircher and } \\
\text { Florian Huber }\end{array}$ & 195 & $\begin{array}{l}\text { The International Transmission of U.S. } \\
\text { Structural Shocks - Evidence from Global } \\
\text { Vector Autoregressions }\end{array}$ \\
\hline $\begin{array}{l}\text { September 16, } \\
2014\end{array}$ & $\begin{array}{l}\text { Kim P. Huynh, } \\
\text { Philipp Schmidt- } \\
\text { Dengler, } \\
\text { Helmut Stix }\end{array}$ & 196 & $\begin{array}{l}\text { The Role of Card Acceptance in the } \\
\text { Transaction; Demand for Money }\end{array}$ \\
\hline $\begin{array}{l}\text { October 10, } \\
2014\end{array}$ & $\begin{array}{l}\text { Martin Brown, } \\
\text { Helmut Stix }\end{array}$ & 197 & $\begin{array}{l}\text { The Euroization of Bank Deposits in Eastern } \\
\text { Europe }\end{array}$ \\
\hline $\begin{array}{l}\text { October 17, } \\
2014\end{array}$ & $\begin{array}{l}\text { Ludmila Fadejeva, } \\
\text { Martin Feldkircher, } \\
\text { Thomas Reininger }\end{array}$ & 198 & $\begin{array}{l}\text { Spillovers from Euro Area and U.S. Credit } \\
\text { and Demand Shocks: Comparing Emerging } \\
\text { Europe on the Basis of a GVAR Model }\end{array}$ \\
\hline $\begin{array}{l}\text { December 18, } \\
2014\end{array}$ & Esther Segalla & 199 & $\begin{array}{l}\text { Shock Transmission through International } \\
\text { Banks: Austria }\end{array}$ \\
\hline $\begin{array}{l}\text { March 5, } \\
2015\end{array}$ & $\begin{array}{l}\text { Jonas Dovern, } \\
\text { Martin Feldkircher, } \\
\text { Florian Huber }\end{array}$ & 200 & $\begin{array}{l}\text { Does Joint Modelling of the World Economy } \\
\text { Pay Off? Evaluating Global Forecasts from a } \\
\text { Bayesian GVAR }\end{array}$ \\
\hline $\begin{array}{l}\text { May 19, } \\
2015\end{array}$ & Markus Knell & 201 & $\begin{array}{l}\text { The Return on Social Security with } \\
\text { Increasing Longevity }\end{array}$ \\
\hline $\begin{array}{l}\text { June 15, } \\
2015\end{array}$ & Anil Ari & 202 & Sovereign Risk and Bank Risk-Taking \\
\hline $\begin{array}{l}\text { June 15, } \\
2015\end{array}$ & Matteo Crosignani & 203 & $\begin{array}{l}\text { Why Are Banks Not Recapitalized During } \\
\text { Crises? }\end{array}$ \\
\hline $\begin{array}{l}\text { February 19, } \\
2016\end{array}$ & Burkhard Raunig & 204 & Background Indicators \\
\hline $\begin{array}{l}\text { February 22, } \\
2016\end{array}$ & $\begin{array}{l}\text { Jesús Crespo } \\
\text { Cuaresma, } \\
\text { Gernot Doppelhofer, } \\
\text { Martin Feldkircher, } \\
\text { Florian Huber }\end{array}$ & 205 & US Monetary Policy in a Globalized World \\
\hline
\end{tabular}




\section{Call for Entries: \\ Visiting Research Program}

The Oesterreichische Nationalbank (OeNB) invites applications from external researchers for participation in a Visiting Research Program established by the OeNB's Economic Analysis and Research Department. The purpose of this program is to enhance cooperation with members of academic and research institutions (preferably post-doc) who work in the fields of macroeconomics, international economics or financial economics and/or with a regional focus on Central, Eastern and Southeastern Europe.

The OeNB offers a stimulating and professional research environment in close proximity to the policymaking process. Visiting researchers are expected to collaborate with the OeNB's research staff on a prespecified topic and to participate actively in the department's internal seminars and other research activities. They will be provided with accommodation on demand and habe, as a rule, access to the department's data and computer resources and to research assistance. Their research output may be published in one of the department's publication outlets or as an OeNB Working Paper. Research visits should ideally last between 3 and 6 months, but timing is flexible.

Applications (in English) should include

- a curriculum vitae,

- a research proposal that motivates and clearly describes the envisaged research project,

- an indication of the period envisaged for the research visit, and

- information on previous scientific work.

Applications for 2016 should be e-mailed to eva.gehringer-wasserbauer@oenb.at by May 1, 2016.

Applicants will be notified of the jury's decision by mid-June. The following round of applications will close on November 1, 2016. 